\title{
Article \\ Nanomagnetic Actuation of Hybrid Stents for Hyperthermia Treatment of Hollow Organ Tumors
}

\author{
Benedikt Mues ${ }^{1}\left(\mathbb{D}\right.$, Benedict Bauer $^{2}$, Anjali A. Roeth ${ }^{3}$, Jeanette Ortega ${ }^{2}$, Eva Miriam Buhl ${ }^{4}\left(\mathbb{D}\right.$, Patricia Radon $^{5}$, \\ Frank Wiekhorst ${ }^{5}\left(\mathbb{B}\right.$, Thomas Gries ${ }^{2}$, Thomas Schmitz-Rode ${ }^{1}(\mathbb{D})$ and Ioana Slabu ${ }^{1, *(1)}$
}

1 Institute of Applied Medical Engineering, Helmholtz Institute, Medical Faculty, RWTH Aachen University, Pauwelsstraße 20, 52074 Aachen, Germany; mues@ame.rwth-aachen.de (B.M.); smiro@ame.rwth-aachen.de (T.S.-R.)

2 Institut für Textiltechnik, RWTH Aachen University, Otto-Blumenthal-Straße 1, 52074 Aachen, Germany; benedict.bauer@ita.rwth-aachen.de (B.B.); jeanette.ortega@ita.rwth-aachen.de (J.O.); thomas.gries@ita.rwth-aachen.de (T.G.)

3 Department of General, Visceral and Transplant Surgery, RWTH Aachen University Hospital, Pauwelsstraße 30, 52074 Aachen, Germany; aroeth@ukaachen.de

4 Institute of Pathology, Electron Microscopy Facility, RWTH University Hospital Aachen, Pauwelsstraße 30, 52074 Aachen, Germany; ebuhl@ukaachen.de

5 Physikalisch-Technische Bundesanstalt, Abbestraße 2-12, 10587 Berlin, Germany; patricia.radon@ptb.de (P.R.); Frank.Wiekhorst@ptb.de (F.W.)

* Correspondence: slabu@ame.rwth-aachen.de; Tel.: +49-241-80-89102

Citation: Mues, B.; Bauer, B.; Roeth, A.A.; Ortega, J.; Buhl, E.M.; Radon, P.; Wiekhorst, F.; Gries, T.; Schmitz-Rode, T.; Slabu, I. Nanomagnetic Actuation of Hybrid Stents for Hyperthermia Treatment of Hollow Organ Tumors. Nanomaterials 2021, 11, 618.

https://doi.org/10.3390/nano11030618

Academic Editor: Jörg Schnorr

Received: 29 January 2021

Accepted: 24 February 2021

Published: 2 March 2021

Publisher's Note: MDPI stays neutral with regard to jurisdictional claims in published maps and institutional affiliations.

Copyright: (c) 2021 by the authors. Licensee MDPI, Basel, Switzerland. This article is an open access article distributed under the terms and conditions of the Creative Commons Attribution (CC BY) license (https:/ / creativecommons.org/licenses/by/ $4.0 /)$.

\begin{abstract}
This paper describes a magnetic nanotechnology that locally enables hyperthermia treatment of hollow organ tumors by using polymer hybrid stents with incorporated magnetic nanoparticles (MNP). The hybrid stents are implanted and activated in an alternating magnetic field to generate therapeutically effective heat, thereby destroying the tumor. Here, we demonstrate the feasibility of nanomagnetic actuation of three prototype hybrid stents for hyperthermia treatment of hollow organ tumors. The results show that the heating efficiency of stent filaments increases with frequency from approximately $60 \mathrm{~W} / \mathrm{g}_{\mathrm{Fe}}(95 \mathrm{kHz})$ to approximately $250 \mathrm{~W} / \mathrm{g}_{\mathrm{Fe}}(270 \mathrm{kHz})$. The same trend is observed for the variation of magnetic field amplitude; however, heating efficiency saturates at approximately $30 \mathrm{kA} / \mathrm{m}$. MNP immobilization strongly influences heating efficiency showing a relative difference in heating output of up to $60 \%$ compared to that of freely dispersed MNP. The stents showed uniformly distributed heat on their surface reaching therapeutically effective temperatures of $43^{\circ} \mathrm{C}$ and were tested in an explanted pig bile duct for their biological safety. Nanomagnetic actuation of hybrid stents opens new possibilities in cancer treatment of hollow organ tumors.
\end{abstract}

Keywords: magnetic nanoparticles; hyperthermia efficiency; hybrid implants; Brownian relaxation; Néel relaxation; stents; tumor therapy

\section{Introduction}

For patients with tumors of endoluminal organs, e.g., tracheobronchial carcinoma, esophagus adenocarcinoma, or bile duct Klatskin tumors, life-threatening situations arise due to tumor ingrowth and thereby occlusion of the hollow organ [1-4]. In approximately $20 \%$ of the cases, such tumors are non-resectable, and treatments are restricted to implantation of metallic or plastic stents to widen the occluded endoluminal site $[5,6]$. However, usually due to tumor tissue ingrowth, a narrowing of the hollow organs, so-called restenosis or reocclusion, develops [7,8]. In order to prevent this, magnetic fluid hyperthermia (MFH) treatment can be employed. In this way, therapeutically effective heat with temperatures in a range of 42 to $46^{\circ} \mathrm{C}$ is generated, destroying tumor cells via apoptosis $[9,10]$. Magnetic nanoparticles (MNP) are known as promising heating agents suitable for the design of hybrid materials and textile implants with controllable heat output and specific saturation temperatures and, therefore, are widely investigated for cancer treatment by 
MFH. MNP have been also be used in tumor treatment by photothermia due to their ability to convert the energy of absorbed light into heat [11,12]. As heat enhances tumor sensitivity, MFH was also investigated in combination with other cancer treatments such as hadron therapy [13] or immune therapy [14]. The technology of nanoparticle incorporation into textiles enhancing their functionality such as UV resistance, antimicrobial properties, or magnetic guidance was reported previously [15-17]. MNP inside implant materials were used before as contrast agents to visualize implant structure and functionality with magnetic resonance imaging (MRI) [18-20]. Such engineered materials loaded with MNP are also known as magnetic scaffolds. Biodegradable magnetic scaffolds made of polymers such as chitosan-glycerophosphate, poly(L-lactic acid) (PLLA), or poly-caprolactone (PCL) have been widely investigated in tissue engineering for nerve regeneration [21], improvement of wound healing after surgical resection of a malignant skin tumor [22], and design of cardiac tissue [23]. Fibrous magnetic scaffolds are particularly suitable for designing smart hyperthermia nanofiber platforms to combine drug and heat release [24-27]. In the case of bone tissue engineering, magnetic scaffolds of biodegradable polymers (e.g., PCL, gelatin) and ceramics (e.g., hydroxyapatite, akermanite) have been investigated to avoid recurrence of bone tumors after surgery by local hyperthermia treatment [28-30]. In this way, a temperature increase of $20^{\circ} \mathrm{C}$ was achieved, resulting in a survival fraction of only $30 \%$ of VX2 cancer cells after treatment [31].

To enable MFH, the MNP are excited in an alternating magnetic field (AFM), transforming its energy into heat via magnetic relaxation processes (Néel and Brownian relaxation). To facilitate local MFH treatment on cellular level, MNP are usually directly injected into the tumor [32] or accumulated at the tumor site via magnetic targeting [33]. There, MNP interactions with cancer cells play an important role regarding their heat release inside the cell [34]. Recently, it was shown that MNP binding to the cell surface and internalization of bigger MNP agglomerates inside the cells leads to a loss in MNP heating efficiency, especially because of the absence of Brownian relaxation contributions to the overall magnetic relaxation process $[35,36]$. MNP agglomeration was demonstrated to have an enhancing effect, while MNP immobilization was shown to cause a drop in heating efficiency [37,38]. Along the same lines, gradual immobilization of MNP inside hydrogels led to a loss in heating efficiency by one third [39]. These characteristics of heating performance are a result of a complex interplay between field parameters, MNP immobilization, and agglomeration. There are two established MNP heating theories, linear response theory (LRT) and Stoner-Wohlfarth model based theory (SWMBT), describing the MFH physics [40]. However, they lack comprehensive implementation of MNP dynamic relaxation processes. To account for the interaction phenomena and the absence of the Brownian relaxation in magnetic scaffolds, the so-called Cole-Cole model, an extension of the Debye model used in the LRT, was suggested for the description of the relaxation dynamics [41-43]. With this model, the temperature increase of magnetic scaffolds activated in an AMF was explained based on a smooth decrease of MNP susceptibility for increasing frequency. This differs from the expectations for dispersed MNP, which exhibit a peak susceptibility as described with the Debye model $[41,44]$. A similar change of the susceptibility was also observed for MNP embedded in hydrogel [45]. Further, advanced stochastic non-equilibrium magnetic relaxation simulations provided a deeper understanding of the fundamentals of MNP magnetic relaxation processes in AMF $[46,47]$. In such simulations, the heating efficiency was determined in dependency of MNP magnetic size and anisotropy energy constants as well as of the AFM parameters. In Monte-Carlo simulations, the effects of MNP immobilization and interactions on MFH were also investigated [48].

Similar to magnetic scaffolds, immobilization and agglomeration of MNP inside hybrid materials and filaments used for the design of implants change their heating properties. The presence of MNP agglomerates inside filaments after a melt-spinning process was reported before [18]. In this case, MNP are fully immobilized, and Brownian rotation can be considered as blocked. In order to optimize hyperthermia performance of hybrid implants, AMF parameters (amplitude, frequency) must be adjusted with respect 
to MNP properties (size, magnetization) so that the contribution of Néel relaxation to the heating efficiency is maximized. According to previous reports, for a Néel dominated magnetic relaxation, small MNP sizes (<20 nm) in combination with an AMF frequency of about $100 \mathrm{kHz}$ are most suitable parameters to enhance the MFH performance [49-51].

For MFH treatment of hollow organ tumors, we developed hybrid polypropylene (PP) stents with incorporated magnetic nanoparticles (MNP), to enable local heat by their nanomagnetic actuation in an AMF. A similar approach of tumor treatment by heat induction in metallic stents was investigated before; however, the energy uptake from the AMF was not sufficient, and the control of temperature was difficult, resulting in unintended extent of necrosis $[52,53]$. Compared to previous works on magnetic scaffolds, we present a non-degradable prototype polymer stent combining local hyperthermia and mechanical widening of hollow organs. In the present work, we evaluate the heating performance of hybrid filaments and braided stents with three different MNP concentrations depending on various AMF parameters. The heating performance at three different frequencies $(95,140$, and $270 \mathrm{kHz}$ ) and at different magnetic field amplitudes varying from 14 to $65 \mathrm{kA} / \mathrm{m}$ is determined. MNP are thoroughly characterized, and the relevant properties are discussed, especially regarding the MNP agglomeration and immobilization inside the filaments as well as their magnetic relaxation in static and alternating magnetic fields. Finally, the feasibility of achieving therapeutic temperatures of approximately $43^{\circ} \mathrm{C}$ at the surface of three prototype stents designed for the bile duct is demonstrated, and the biological safety of such a stent placed in a porcine bile duct is evaluated by histological examination.

\section{Materials and Methods}

\subsection{Materials}

For the synthesis of the MNP, the chemicals iron(III) chloride hexahydrate $\left(\mathrm{FeCl}_{3} \cdot 6 \mathrm{H}_{2} \mathrm{O}\right.$, p.a., $\geq 99 \%$, Sigma-Aldrich, Darmstadt, Germany), iron(II) chloride tetrahydrate $\left(\mathrm{FeCl}_{2} \cdot 4 \mathrm{H}_{2} \mathrm{O}\right.$, p.a., $\geq 98 \%$, Sigma-Aldrich, Darmstadt, Germany), ammonium hydroxide $\left(\mathrm{NH}_{4} \mathrm{OH}, \mathrm{ACS}\right.$ reag., 28-30\%, Sigma-Aldrich, Darmstadt, Germany), and lauric acid $\left(\mathrm{C}_{12} \mathrm{H}_{24} \mathrm{O}_{2}>98 \%\right.$, FCC, Sigma-Aldrich, Darmstadt, Germany) were used. The chemicals acrylamide (Aam, $\geq 99 \%$, Sigma-Aldrich, Darmstadt, Germany), N,N'-methylenebisacrylamide (BIS, 99\%, Sigma-Aldrich, Darmstadt, Germany), ammonium peroxodisulfate (APS, $\geq 98 \%$, AppliChem, Darmstadt, Germany), and $\mathrm{N}, \mathrm{N}, \mathrm{N}^{\prime}, \mathrm{N}^{\prime}$-tetramethylethylene-diamine (TEMED, $99 \%$, Sigma-Aldrich, Darmstadt, Germany) were used for the synthesis of the acrylamide hydrogel. Technical grade polypropylene (PP) pellets (Moplen HP561R) were purchased from LyondellBasell Industries N.V. (Rotterdam, Netherlands). Agarose (Carl Roth, Karlsruhe, Germany) was used to prepare a tissue-like gel environment in which the inductive heating experiments were carried out. For the cytotoxicity tests, RPMI cell culture medium (21875-034, Life Technologies, Carlsbad, CA, USA) and CellTiter-Glo 2.0 assay (G7570, Promega, Madison, WI, USA) were used.

\subsection{Synthesis of MNP}

First, lauric acid coated iron oxide magnetite $\left(\mathrm{Fe}_{3} \mathrm{O}_{4}\right)$ nanoparticles were synthesized via the co-precipitation of $\mathrm{Fe}^{2+}$ and $\mathrm{Fe}^{3+}$ ions (molar ratio $\mathrm{Fe}^{2+} / \mathrm{Fe}^{3+}$ of $1 / 2$ ) in the presence of a base as described in [54]. Briefly, $16 \mathrm{~g} \mathrm{FeCl}_{3}$ and $8 \mathrm{~g} \mathrm{FeCl}_{2}$ were dissolved in $67.4 \mathrm{~mL}$ deionized water. Subsequently, $33.4 \mathrm{~mL}$ of $\mathrm{NH}_{4} \mathrm{OH}$ were added dropwise under constant stirring at room temperature. The precipitated MNP were washed several times with $100 \mathrm{~mL}$ of a $0.7 \mathrm{M} \mathrm{NH}_{4} \mathrm{OH}$ solution to remove the chloride ions. For the coating, the resulting MNP suspension was heated up in an oil bath at $90^{\circ} \mathrm{C}$, and $3.0 \mathrm{~g}$ lauric acid was added under constant stirring. The MNP suspension was cooled down to room temperature and centrifuged for $15 \mathrm{~min}$ at $4000 \mathrm{rpm}$ with a Rotina 420R Centrifuge (Thermo Scientific Inc., Waltham, MA, USA). Subsequently, the in water dispersed MNP (in the following denoted as MNP disp) were freeze-dried at $-85^{\circ} \mathrm{C}$ and $0.04 \mathrm{mbar}$ in a lyophilisator (Alpha 2-4 LDplus, Martin Christ Gefriertrocknungsanlagen $\mathrm{GmbH}$, Osterode, Germany) for at least $12 \mathrm{~h}$, resulting in an MNP powder. 


\subsection{Synthesis of Acrylamide Hydrogels with MNP}

The MNP were immobilized inside acrylamide hydrogels (in the following denoted as MNP immob) with an adjustable mesh size as described in literature [39]. For the preparation of a hydrogel with a mean mesh size of approximately $10 \mathrm{~nm}$, a polymer volume fraction of $v_{\mathrm{pol}}=\left(\rho^{-1} \mathrm{Aam}\left(m_{\mathrm{Aam}}+m_{\mathrm{BIS}}\right)\right) /\left(\rho^{-1} \mathrm{H}_{2} \mathrm{O}_{\mathrm{tot}}\right)=8 \%$ and a crosslinker mole fraction of $\alpha=n^{-1}$ BIS $\left(n_{\text {BIS }}+n_{\text {Aam }}\right)=1 \%$ were used. Here, $\rho_{\text {Aam }}=1.3 \mathrm{~g} \cdot \mathrm{cm}^{-3}$ and $\rho_{\mathrm{H} 2 \mathrm{O}}=1.0 \mathrm{~g} \cdot \mathrm{cm}^{-3}$ denote the density of polyacrylamide and deionized water, respectively [55]. Further, $m_{\text {Aam }}$, $m_{\mathrm{BIS}}, m_{\mathrm{tot}}$, are the masses of Aam, BIS, and the mass of total solution, while $n_{\mathrm{BIS}}$ and $n_{\mathrm{Aam}}$ denote the amount of substance of BIS and Aam. For the preparation, Aam and BIS were completely dissolved in water. Subsequently lauric acid stabilized MNP were added to the solution and vortexed several times. In order to initialize and catalyze the free radical polymerization, mass fractions $0.2 \%$ of APS as well as TEMED were added to the solution, respectively. The polymerization was kept for $2 \mathrm{~h}$ at room temperature. All amounts were selected to reach a resulting sample volume of $1 \mathrm{~mL}$ with an iron concentration of $1.1 \mathrm{mg}(\mathrm{Fe}) / \mathrm{mL}$ for the purposes of comparability.

\subsection{Production of PP Filaments and Stents}

Three different hybrid filaments were produced by melt-spinning of PP pellets with $3 \%(w / w), 5 \%(w / w)$, and 7\%(w/w) freeze-dried MNP (in the following denoted as PP@3\%MNP, PP@5\%MNP, and PP@7\%MNP). For that, PP pellets and MNP were melt-spun at $230{ }^{\circ} \mathrm{C}$ and processed with a twin-screw extruder (MC 15 Micro Compounder, Xplore Instruments BV, Sittard, Netherlands), forming a homogeneous mixture that was pressed through a nozzle. Subsequently, $30 \mathrm{~cm}$ of the hybrid filaments PP@3\%MNP, PP@5\%MNP, and PP@7\%MNP were braided into stents (in the following denoted as St@3\%MNP, St@5\%MNP, and $\mathrm{St} @ 7 \% \mathrm{MNP}$ ) and heat set at $140{ }^{\circ} \mathrm{C}$ for $30 \mathrm{~min}$.

\subsection{Transmission Electron Microscopy (TEM)}

The core diameters $d_{\text {core }}$ of the MNP and the MNP agglomerates inside the PP filaments were investigated via TEM with a Zeiss LEO 906 microscope (Carl Zeiss GmbH, Oberkochen, Germany) operated at $60 \mathrm{kV}$. For the dispersed MNP, $1 \mu \mathrm{L}$ of the sample was pipetted on formvar-carbon-coated nickel grids (200 mesh) (Electron Microscopy Sciences, Hatfield, PA, USA) and air-dried under ambient conditions. For the spherical shaped MNP, the core diameter $d$ of about 150 particles was measured using the software GIMP and fitted with the cumulative log-normal distribution probability density function (CDF) from which the mean and variance are calculated (see Supplementary Materials S1). The PP filaments were embedded in epon resin, cut into thin slices using a diamond cutter, and placed on nickel grids. For the evaluation of ellipsoidal MNP agglomerates inside the PP filaments, both the major and the minor axis of about 150 agglomerates were measured. The mean core or agglomerate size was obtained by fitting the CDF to the measured data.

\subsection{Dynamic Light Scattering (DLS)}

The hydrodynamic diameter $d_{\mathrm{h}}$ of MNP dispersed in deionized $\mathrm{H}_{2} \mathrm{O}$ was measured by DLS using a Zetasizer Nano S (Malvern Instruments Ltd., Worcestershire, UK) at a wavelength of $\lambda=633 \mathrm{~nm}$ (detection angle of $173^{\circ}$ ). All measurements were performed at $20^{\circ} \mathrm{C}$ and repeated a total of three times. The mean and variance of the hydrodynamic size are obtained by fitting the log-normal distribution probability density function (PDF) to the measured intensity data (see Supplementary Materials S1).

\subsection{X-ray Diffraction (XRD)}

To investigate the as synthesized MNP crystal structure and crystalline size $d_{\text {cryst, }}$ XRD measurements were performed. For this, an X'pert diffractometer (PANalytical B.V., Almelo, Netherlands) was operated at a wavelength of $\lambda_{\mathrm{K} \alpha}=1.5 \AA$ of a copper anode and an acceleration current of $I=40 \mathrm{kA}$. For the preparation, a glass substrate, which was cleaned in acetone and isopropanol, was covered with $100 \mu \mathrm{L} 0.1 \%$ poly-L-lysine. 
Dispersed MNP were pipetted on the substrate and air-dried under ambient conditions. Grazing incident measurements were performed with a constant incident angle $\omega=0.7^{\circ}$, and the diffracted signal was recorded in increments of $0.02^{\circ}$ over a rage of $2 \theta=\left(20^{\circ}-70^{\circ}\right)$. The XRD measurements for the MNP resulted in an intensity profile of the diffracted X-rays. The Bragg angles were determined using the pseudo-Voigt function as a fitting model [56] (see Supplementary Materials S1). Further, the MNP crystalline size $d_{\text {cryst }}$ was determined using the modified Scherrer equation [57] (see Supplementary Materials S1).

\subsection{Iron Concentration Determination}

The iron concentration inside the PP filaments was examined by thermogravimetric analysis (TGA) using a STARe System TGA/DSC1 (Mettler Toledo GmbH, Gießen, Germany) and by photometric absorption (PA) measurements using a Spectrometer Ultrospec 2100 pro (Biochrom Ltd., Cambridge United Kingdom). For the TGA measurements, the samples were continuously heated $\left(10^{\circ} \mathrm{C} / \mathrm{min}\right)$ up to $800{ }^{\circ} \mathrm{C}$ until the polymer and MNP coating degraded completely. The weight of the residue was allocated to that of iron oxide (magnetite $\mathrm{Fe}_{3} \mathrm{O}_{4}$, see Section 3 Results and Discussion), from which the iron concentration inside the filament was deduced. For PA measurements, the filaments were first treated with $\mathrm{HCl}$ and $\mathrm{HNO}_{3}$ to dissolve the iron ions, and the iron concentration in the solution was determined based on complexation of $\mathrm{Fe}^{3+}$ with Tiron (4,5-Dihydroxy1,3-benzenedisulfonic acid disodium salt monohydrate) [58]. TGA and PA measurement results were used to calculate the weighted average of the iron concentration inside the filaments (see Supplementary Materials S2 Table S2).

\subsection{Cytotoxicity Tests of Hybrid Filaments}

As the hybrid stents are designed for the implantion in patients, it must be ensured that the filaments are not toxic to cells and do not cause cell damage. Therefore, the toxic effect on cells, so-called cytotoxicity, of the filaments PP@3\%MNP, PP@5\%MNP, and PP@7\%MNP was tested using the mouse fibroblast cell line L929 from the German Collection of Microorganisms and Cell-Cultures. This cell line was chosen according to ISO 10993-5, as it is sensitive towards toxic effects. It is, therefore, used for cytotoxic testing, independent from the target tissue [59-64]. For pretreatment, the cells were seeded with Roswell Park Memorial Institute (RPMI) medium with $10 \%(v / v)$ fetal calf serum (FCS) and $1 \%(v / v)$ Penicillin/Streptomycin. Approximately $0.5 \mathrm{mg}$ of each filament was disinfected and magnetically fixed on the ground of a well. After that, a cell suspension with 10,000 L929 cells in RPMI medium was added to the filaments and incubated at $37^{\circ} \mathrm{C}$ and $5 \% \mathrm{CO}_{2}$ for $24 \mathrm{~h}$. Then, the supernatant was removed, and equal amount of RPMI medium as well as CellTiter-Glo were added. The CellTiter-Glo assay is based on the quantification of ATP produced by metabolically active cells. After cell lysis, a luminescent signal is generated, which is proportional to the amount of ATP and is recorded at an integration time of $1 \mathrm{~s}$ per well. The luminescence signal was recorded using a Synergy HT Microplate Reader (BioTek Instruments Inc., Winooski, VT, USA). All tests were performed in triplicates. Cells incubated without filaments were used as a positive control and cells incubated with $10 \%(v / v)$ dimethylsulfoxide (DMSO) solution as a negative control.

\subsection{Magnetic Characterization in Static and Alternating Fields}

The magnetic properties of the samples were characterized using a SQUID magnetometer MPMS 5S (LOT Quantum Design, San Diego, CA, USA). For the preparation of as synthesized MNP, $30 \mu \mathrm{L}$ of the sample was mixed with $30 \mu \mathrm{L} 15 \%(w / w)$ mannitol solution in a polycarbonate (PC) capsule and freeze dried at $-85^{\circ} \mathrm{C}$ and $0.04 \mathrm{mbar}$ in a lyophilisator (Alpha 2-4 LDplus, Martin Christ Gefriertrocknungsanlagen $\mathrm{GmbH}$, Osterode, Germany) for $12 \mathrm{~h}$. The PP filaments were weighed and measured inside Teflon capsules placed in the sample holder. For the determination of the saturation magnetization values, magnetization measurements were performed at $295 \mathrm{~K}$, varying the field strength from zero to $4 \cdot 10^{6} \mathrm{~A} / \mathrm{m}$. From the fit with the Langevin function, the saturation magnetization $M_{\mathrm{S}}$ was determined 
(see Supplementary Materials S1). In order to determine the particle magnetic size $d_{\mathrm{m}}$, so-called Chantrell fitting according to literature was performed assuming log-normal distributed MNP sizes [65,66]. The ZFC magnetization curves were obtained by measuring the magnetization in a magnetic field of $796 \mathrm{~A} / \mathrm{m}$, while the temperature was stepwise increased from 5 to $295 \mathrm{~K}$. The FC magnetization curves were obtained by magnetization measurements at the same field as for ZFC measurements, while the temperature was stepwise decreased from 295 to $5 \mathrm{~K}$.

Magnetic particle spectroscopy (MPS) measurements were carried out using a commercial spectrometer (Bruker BioSpin MRI GmbH, Ettlingen, Germany) operated at $H=25 \mathrm{mT} / \mu_{0}$, $f=25 \mathrm{kHz}$, and $37^{\circ} \mathrm{C}$. A sample volume of $10 \mu \mathrm{L}$ dispersed MNP as well as PP filaments were measured inside PCR tubes. From the measured amplitude spectrum (higher harmonics $\left.A_{n}(n f), n=3,5,7, \ldots\right)$, the concentration independent amplitude ratio $A_{5} / A_{3}$ was determined, which is an indicator of the state and environment of an MNP sample $[67,68]$.

Alternating current susceptibility (ACS) was measured using a DynoMag susceptometer (RISE Acreo, Gothenburg, Sweden) covering a frequency range of $1 \mathrm{~Hz}$ to $500 \mathrm{kHz}$ with a AC field amplitude of $360 \mathrm{~A} / \mathrm{m}$. The field amplitude of $360 \mathrm{~A} / \mathrm{m}$ is stable up to a frequency of $15 \mathrm{kHz}$ and then continuously decreases with increasing frequency to $20 \mathrm{~A} / \mathrm{m}$ (at $500 \mathrm{kHz}$ ). Measurements were performed with $100 \mu \mathrm{L}$ dispersed MNP at $295 \mathrm{~K}$. The real $\chi^{\prime}(f)$ and imaginary $\chi^{\prime \prime}(f)$ magnetic susceptibility was acquired.

\subsection{Characterization of Heating Efficiency}

The inductive heating experiments were performed with a custom-build hyperthermia setup (Trumpf Hüttinger GmbH + Co. KG, Freiburg, Germany), which consists of a DC generator, an AC-resonant oscillator, and a water-cooled copper coil (inductor). For the experiments, an AMF was generated with frequencies of 95, 140, and $270 \mathrm{kHz}$, respectively, and field amplitudes ranging from 14 to $65 \mathrm{kA} / \mathrm{m}$. The field parameters (frequency and field amplitude) were verified by measurements with a magnetic field probe (NanoScience Laboratories Ltd., Larchwood, UK). A sample volume of $1 \mathrm{~mL}$ was prepared in $4 \mathrm{~mL}$ glass vials, placed in the center of the inductor, and exposed to the AMF for 30 min starting at an initial temperature of $T_{0}=37^{\circ} \mathrm{C}$. In order to prevent vaporization of water, each glass vial was covered with parafilm during the measurement. The temperature was recorded with a fiber optical sensor (Luxtron 812, LumaSense Technologies Inc., Santa Clara, CA, USA). The dispersed MNP were diluted to an iron concentration of $1.1 \mathrm{mg}(\mathrm{Fe}) / \mathrm{mL}$, which corresponds to the iron concentration of the PP@3\%MNP filaments. An amount of $50 \mathrm{mg}$ (approximately $1 \mathrm{~mm}$ long) PP filaments was stacked in the form of a thin layer and placed inside $1 \mathrm{~mL}$ agarose hydrogel with a monomer mass fraction of $1.5 \%(w / w)$. A drawing and an exemplary photograph of a sample are available in Supplementary Materials S3 (Figure S3). Each hybrid stent was placed vertically in a plastic tube and subsequently embedded in $10 \mathrm{~mL}$ agarose hydrogel (approximately $1 \mathrm{~mm}$ of the stent edges protrude from the hydrogel). For the preparation of the agarose hydrogel, agarose was mixed with deionized water, heated up to $90{ }^{\circ} \mathrm{C}$ for $30 \mathrm{~min}$ and cooled down under ambient conditions after preparation. For background subtraction, reference measurements of water and agarose hydrogel were performed for each AMF setting. The measured temperature data, $T(t)$, was fitted with the Box-Lucas function to determine the specific loss power value (SLP) [69] (see Supplementary Materials S1). The temperature profile during heat dissipation in the surroundings of the hybrid stents was continuously recorded using a thermographic camera (testo 882, Testo SE \& Co.KG, Titisee-Neustadt, Germany) with an emission coefficient $\alpha=0.96$. The temperature difference was illustrated after background subtraction. The thermographic camera results were validated by simultaneous temperature measurement at the stent surface using a fiber-optic thermometer. For the investigation of heating efficiency, the ambient conditions were kept constant, and the field settings were controlled before each measurement. The measurements were performed following a standardized protocol. The uncertainty analysis includes the uncertainty of 
MNP concentration determination as well as the slight variations of the AMF parameters and of the ambient conditions [70].

\subsection{Feasibility of Endoscopic Placement}

A hybrid stent St@5\%MNP was placed into the bile duct of a porcine cadaver after explantation of the bile duct and its surrounding tissues. The animal cadaver was taken from other approved animal experiments directly after euthanization. No additional ethical approval was needed according to German law and in agreement with the LANUV (State Agency for Nature, Environment, and Consumer Protection, North Rhine-Westphalia). All animal-handling procedures were performed in concordance with the Guide for the Care and Use of Laboratory Animals of the National Institutes of Health and followed the guidelines of the Animal Welfare Act. The hybrid stent St@5\%MNP located in the bile duct and the surrounding tissues were then fixated in the described hyperthermia set-up. After hyperthermia treatment at $45^{\circ} \mathrm{C}$ for $1 \mathrm{~h}$, the bile duct tissue was fixed in formalin and cut into slices with a thickness of approximately $2-3 \mu \mathrm{m}$. The samples were dewaxed using alcohol-xylene series. For H\&E staining, first undiluted Mayer's hematoxylin (Merck, Darmstadt, Germany) and subsequently 1\% eosin (Merck, Darmstadt, Germany) were used. The samples were washed in $0.4 \%$ acetic acid and covered with Vitro-Clud (Langenbrinck $\mathrm{GmbH}$, Emmendingen, Germany).

\section{Results and Discussion}

Figure 1 schematically depicts the production process of hybrid filaments via meltspinning of polypropylene (PP) and MNP powder with a twin-screw extruder, the further assembly to stents, as well as their envisaged application for the treatment of hollow organ tumors. Three different hybrid filaments with a diameter of $(450 \pm 80) \mu \mathrm{m}$ and with 3\%(w/w), 5\%(w/w), and 7\%(w/w) MNP loading (denoted as PP@3\%MNP, PP@5\%MNP, and $\mathrm{PP}$ @\%MNP) were successfully produced. Using these filaments, three different stents were braided (denoted as St@3\%MNP, St@5\%MNP, and St@7\%MNP).

(a)

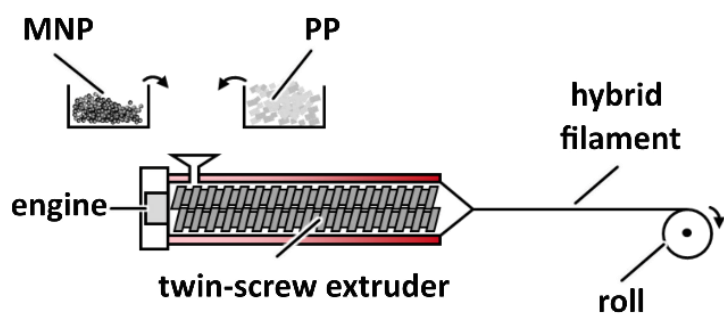

(b)

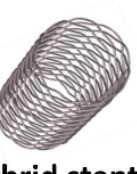

hybrid stent (c)

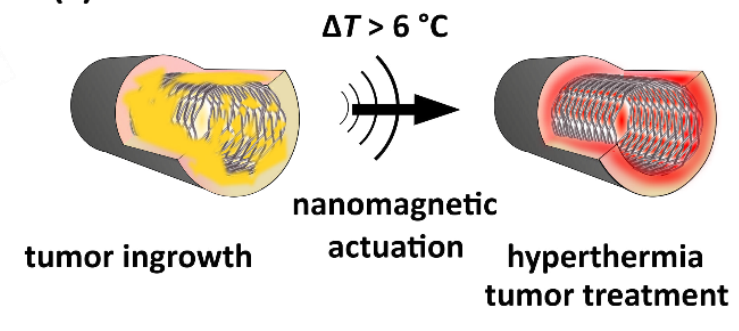

Figure 1. (a) Illustration of the production process of hybrid filaments via melt-spinning of PP pellets and MNP with a twin-screw extruder. (b) Sketch of a hybrid stent. (c) Illustration of hyperthermia approach to treat hollow organ tumors using a hybrid stent: The MNP inside the stent are actuated in an alternating magnetic field, leading to a temperature increase by more than $6{ }^{\circ} \mathrm{C}$ at the stent surface. This local overheating leads to the destruction of the tumor (colored in yellow) near the stent surface.

\subsection{Physico-Chemical Properties of MNP and Hybrid Filaments}

The basic properties of the dispersed MNP sample as well as of the three hybrid filaments PP@3\%MNP, PP@5\%MNP, and PP@7\%MNP incorporated with 2.7\% (w/w), 4.4\% $(w / w)$, and $7.2 \%(w / w)$ MNP, respectively, are summarized in Table 1. Further details on the iron concentration inside the PP filaments determined by TGA (including the TGA curves) and PA measurements are presented in Supplementary Materials S2 Table S2, respectively, Figure S2. 
Table 1. Physico-chemical properties of MNP dispersed in water (MNP disp) and hybrid filaments (PP@3\%MNP, PP@5\%MNP, and PP@7\%MNP): iron concentration $c_{\mathrm{Fe}}$, core diameter $d_{\text {core }}$ (for the filaments the major and minor axis of agglomerates is specified), hydrodynamic diameter $d_{\mathrm{h}}$, crystal diameter $d_{\text {cryst }}$, magnetic diameter $d_{\mathrm{m}}$, saturation magnetization $M_{\mathrm{S}}$, and maximum temperature $T_{\mathrm{M}}$ in the ZFC curve. $\sigma$ denotes the standard deviation.

\begin{tabular}{ccccc}
\hline Property & MNP Disp & PP@3\%MNP & PP@5\%MNP & PP@7\%MNP \\
\hline$\left(c_{\mathrm{Fe}} \pm \sigma_{\text {core }}\right) / \%(w / w)$ & - & $1.97 \pm 0.11$ & $3.20 \pm 0.11$ & $5.24 \pm 0.11$ \\
$\left(d_{\text {core }} \pm \sigma_{\text {core }}\right) / \mathrm{nm}$ & $11.3 \pm 3.3$ & Maj. Ax.: $181 \pm 71$ & Maj. Ax.: $127 \pm 46$ & Maj. Ax.: $164 \pm 46$ \\
$\left(d_{\mathrm{h}} \pm \sigma_{\mathrm{h}}\right) / \mathrm{nm}$ & $141 \pm 69$ & Min. Ax.: $93 \pm 32$ & Min. Ax.: $60 \pm 20$ & Min. Ax.: $79 \pm 23$ \\
$\left(d_{\text {cryst }} \pm \sigma_{\text {cryst }}\right) / \mathrm{nm}$ & $9.5 \pm 0.4$ & - & - & - \\
$\left(d_{\mathrm{m}} \pm \sigma_{\mathrm{m}}\right) / \mathrm{nm}$ & $10.2 \pm 3.1$ & - & - & - \\
$\left(M_{\mathrm{S}} \pm \sigma_{\mathrm{M}}\right) /\left(\mathrm{Am}{ }^{2} / \mathrm{kg}(\mathrm{Fe})\right)$ & $99.4 \pm 0.8$ & $111 \pm .9 \pm 2.9$ & $10.5 \pm 2.9$ \\
$T_{\mathrm{M}} / \mathrm{K}$ & $\sim 204$ & $\sim 332$ & $98 \pm 3$ & $97 \pm 2$ \\
\hline
\end{tabular}

Figure 2 displays exemplary transmission electron microscopy (TEM) images of dispersed MNP, MNP inside PP@3\%MNP, PP@5\%MNP, and PP@7\%MNP filaments. The images show circular-shaped MNP (Figure 2a) and ellipse-shaped MNP agglomerates (Figure 2b-d).

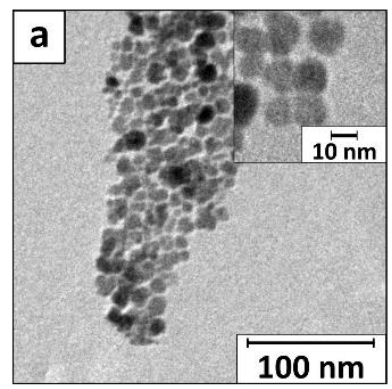

(e)

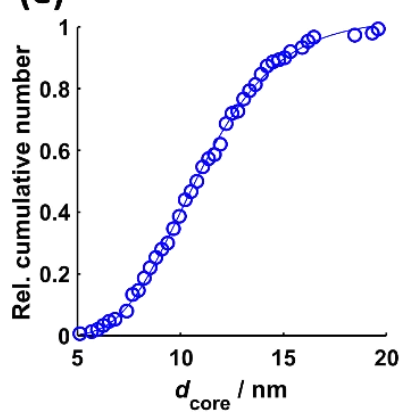

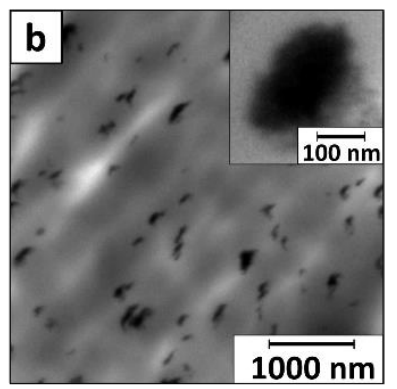

(f)

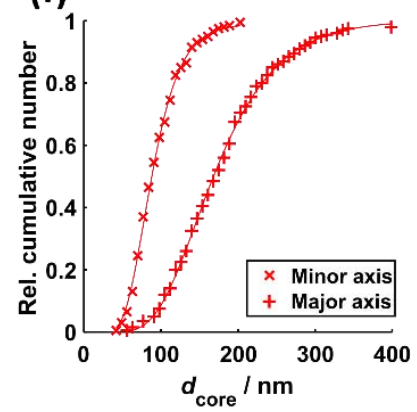

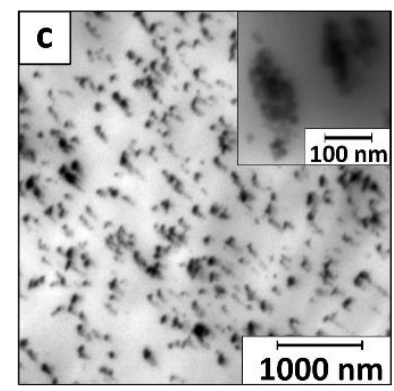

(g)

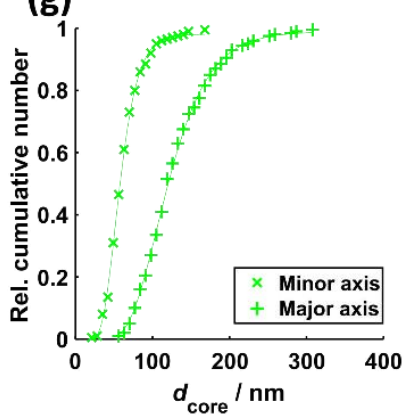

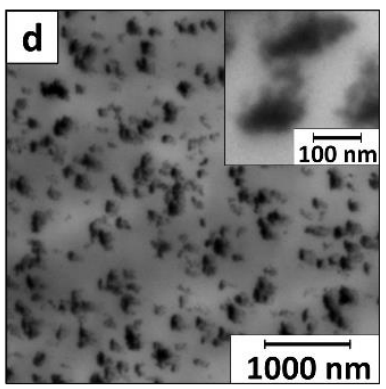

(h)

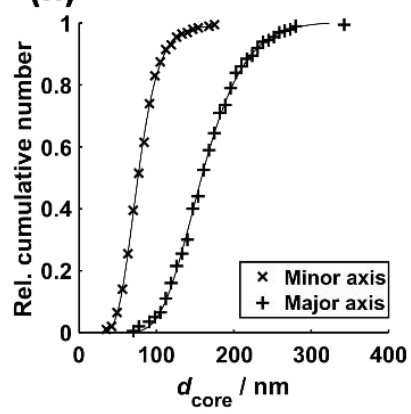

Figure 2. TEM images of (a) MNP disp, (b) MNP inside PP@3\%MNP, (c) PP@5\%MNP, and (d) PP@7\%MNP filaments. The insets show an exemplary magnification of one part of the same image. The corresponding core diameter distribution with a fit to a log-normal CDF of (e) spherical shaped dispersed MNP $\left(R^{2}=0.9987\right),(f)$ minor and major axis of ellipsoidal shaped MNP agglomerated inside PP@3\%MNP $\left(R^{2}{ }_{\text {min }}=0.9984, R^{2}{ }_{\text {maj }}=0.9992\right),(\mathrm{g}) \mathrm{PP} 5 \% \mathrm{MNP}\left(R^{2}{ }_{\min }=0.9991, R^{2}{ }_{\text {maj }}=0.9991\right)$, and (h) PP@7\%MNP filaments $\left(R^{2} \min =0.9995, R^{2}{ }_{\text {maj }}=0.9992\right)$.

The geometry of the MNP agglomerates arises presumably from axial shear stress during the extrusion process, in which the PP and MNP mixture is pressed through a nozzle. The TEM analysis yields log-normal distributed single and agglomerated MNP sizes (Figure 2e-h). For the ellipse-shaped agglomerated MNP, the mean size was analyzed for the major and minor axes (see Figure $2 \mathrm{f}-\mathrm{h}$ ). The results of the mean core size determination are summarized in Table 1. For all filament types, PP@3\%MNP, PP@5\%MNP, and PP@7\%MNP, the ratio between minor and major axis of the MNP agglomerate size is about $1 / 2$. The mean size of the agglomerates is more than ten times higher than the core size of the MNP. Increasing MNP concentration inside the filaments obviously does not lead to the formation of bigger agglomerates (see Table 1 and Figure 3). The largest 
relative difference in the agglomerate sizes is observed for PP@3\%MNP compared to one of PP@5\%MNP (37\% for minor axis and 30\% for the major axis).
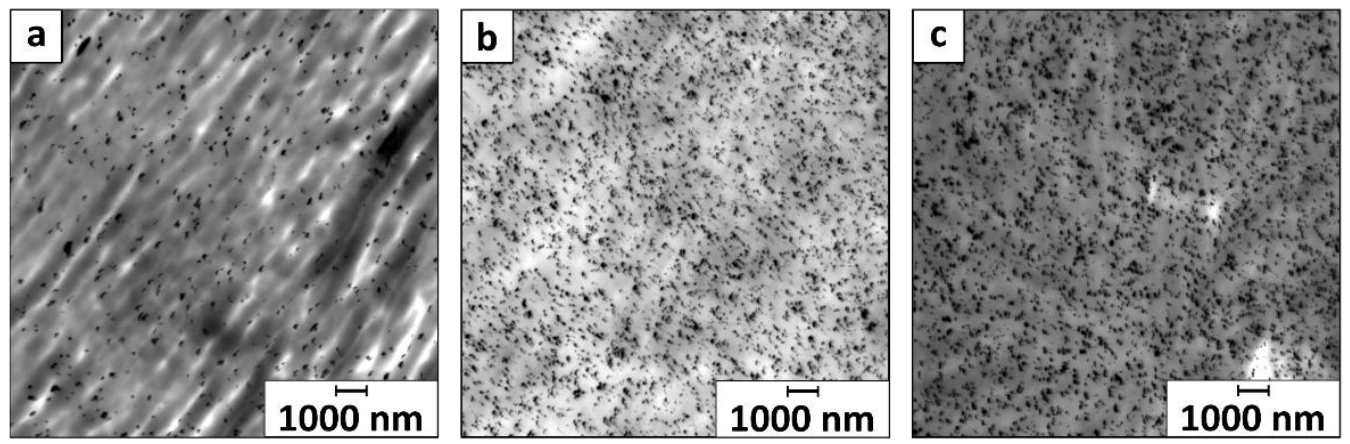

Figure 3. Overview TEM images of (a) MNP inside PP@3\%MNP, (b) PP@5\%MNP, and (c) PP@7\%MNP filaments displayed with a magnification factor of 600 . The displayed area is approximately $225 \mu \mathrm{m}^{2}$.

Exemplary TEM images in Figure 3 display uniformly distributed small MNP agglomerates inside PP@3\%MNP, PP@5\%MNP, and PP@7\%MNP filaments, which according to literature lead to better interfacial interactions and enhanced mechanical properties of the hybrid filaments [71].

Figure 4a shows the result of the DLS measurement for MNP dispersed in water. The PDF fit to the intensity-weighted size distribution of the dispersed MNP yields an MNP hydrodynamic diameter of $d_{\mathrm{h}}=(141 \pm 69) \mathrm{nm}$. The XRD data and Bragg angles are shown in Figure $5 \mathrm{~b}$. The intensity profile between $20^{\circ}$ and $30^{\circ}$ can be attributed to crystalline lauric acid [72]. A clear delineation between a $\mathrm{Fe}_{3} \mathrm{O}_{4}$ and a $\gamma-\mathrm{Fe}_{2} \mathrm{O}_{3}$ crystal structure according to the determined Bragg angles is not feasible. MNP are known to show significant peak broadening and poor statistics in the XRD pattern, which makes it difficult to detect the very small differences in the diffraction intensity patterns of $\mathrm{Fe}_{3} \mathrm{O}_{4}$ and $\gamma-\mathrm{Fe}_{2} \mathrm{O}_{3}$. An investigation of the crystal structure of MNP inside the polymer matrix by XRD measurements is not possible. For that, extensive electron energy loss measurements are necessary [18]. However, the Bragg angles and their corresponding FWHM values were used to determine a weighted average of the crystal size $d_{\text {cryst }}=(9.5 \pm 0.4) \mathrm{nm}$ (see Supplementary Materials S4 Table S4). The result is in line with the findings from TEM measurements $\left(d_{\text {cryst }}=(9.5 \pm 0.4) \mathrm{nm}\right.$, see also Table 1$)$.

(a)

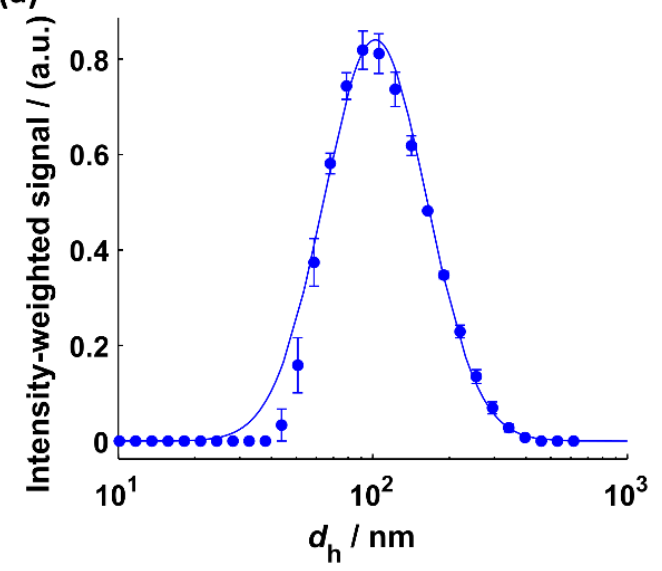

(b)

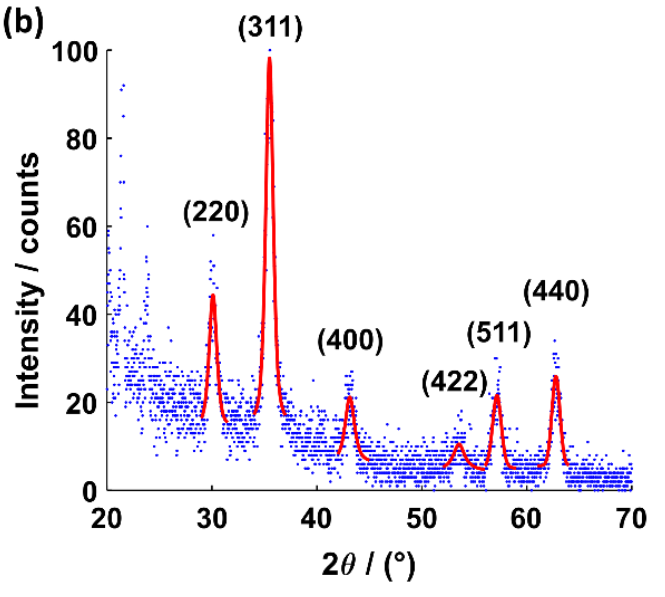

Figure 4. (a) Intensity-weighted size distribution of the hydrodynamic diameters with a fit $\left(R^{2}=0.9973\right)$ to the PDF of a log-normal distribution for the MNP dispersed in water. (b) XRD intensity profile for MNP dispersed in water with a fit of the Pseudo-Voigt function to determine the corresponding Bragg angles (see Supplementary Materials S4 for $R^{2}$ values). 

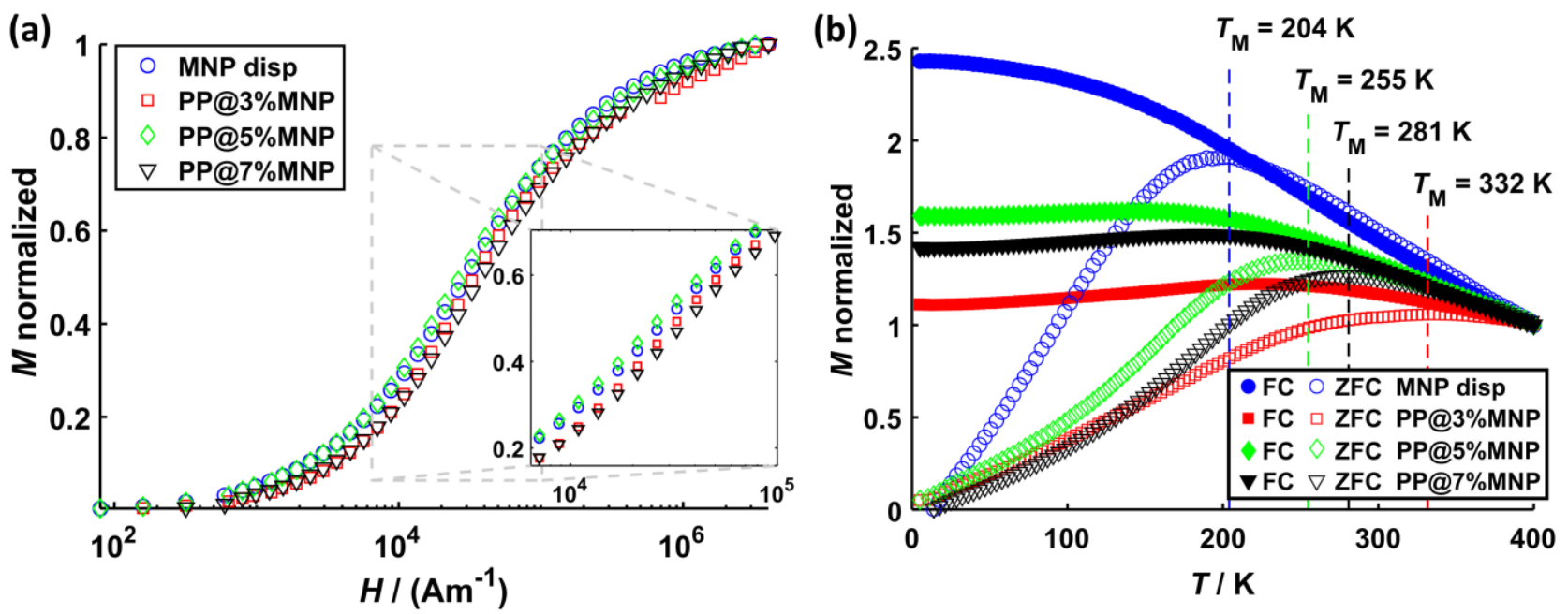

Figure 5. (a) Virgin magnetization curves as well as (b) ZFC (open symbols) and FC (filled symbols) magnetization curves for dispersed MNP, PP@3\%MNP, PP@5\%MNP, and PP@7\%MNP. The virgin curves are normalized to the saturation magnetization, while ZFC/FC curves are normalized to the initial magnetization value of the FC curve.

The normalized magnetization curves for all samples are shown in Figure 5 and the hysteresis curves are shown in Supplementary Materials S5 (Figure S5). The saturation magnetization $M_{\mathrm{S}}$ and the magnetic diameter $d_{\mathrm{m}}$ deduced from these curves as described in Section 2 Materials and Methods are listed in Table 1. From the magnetization curves, it can be deduced that stronger MNP dipole-dipole interactions arise because of agglomerate formation inside the filaments. This is indicated by the slightly lower magnetization values (Figure 5a) as well as by the broader shifted ZFC peaks towards higher temperatures for all PP filaments compared to the one of dispersed MNP. Such effects were associated with dipole-dipole interactions inside nanoclusters before [73-75]. Further, the shift and broadening of the ZFC peak relates to the size of MNP agglomerates and is, for this case, most pronounced for PP@3\%MNP.

The effective anisotropy constant $K_{\text {eff }}$ is estimated from the peak temperatures $T_{\mathrm{M}}$ of the ZCF curve and the magnetic volume $V_{\mathrm{m}}=(\pi / 6) \mathrm{d}_{\mathrm{m}}^{3}$ using the relation $K_{\mathrm{eff}} V_{\mathrm{m}} \approx$ $23.6 k_{\mathrm{B}} T_{\mathrm{M}}[76]$ and yields $K_{\mathrm{eff}} \approx 120 \mathrm{~kJ} / \mathrm{m}^{3}$ (MNP disp), $K_{\mathrm{eff}} \approx 226 \mathrm{~kJ} / \mathrm{m}^{3}$ (PP@3\%MNP), $K_{\text {eff }} \approx 123 \mathrm{~kJ} / \mathrm{m}^{3}$ (PP@5\%MNP), and $K_{\text {eff }} \approx 151 \mathrm{~kJ} / \mathrm{m}^{3}$ (PP@7\%MNP). This is a rough estimation of $K_{\text {eff }}$, which does not take into account effects arising from MNP size distribution or surface anisotropy; however, it qualitatively demonstrates an anisotropy increase with larger MNP agglomeration size, which is in line with the findings in literature $[77,78]$. The high anisotropy values are explained by MNP dipole-dipole interactions inside MNP agglomerates as discussed above. $K_{\text {eff }}$ values from literature of non-interacting magnetite nanoparticles with similar core sizes are in the range of 23 to $41 \mathrm{~kJ} / \mathrm{m}^{3}$ [79].

The results from AC-susceptibility measurements are shown in Figure 6a and display the real $\left(\chi^{\prime}\right)$ and the imaginary $\left(\chi^{\prime \prime}\right)$ part of the volume susceptibility for each sample. Figure $6 \mathrm{~b}$ shows the same results at smaller susceptibility values. $\chi^{\prime \prime}$ values of MNP inside PP@3\%MNP, PP@5\%MNP, and PP@7\%MNP filaments are smaller compared to the ones of dispersed MNP. Only for dispersed MNP, a broad $\chi^{\prime \prime}$ peak occurs at approximately $3 \mathrm{kHz}$. Because of the absence of an $\chi^{\prime \prime}$ peak for MNP immobilized inside the hybrid filaments and with the assumption of magnetically blocked MNP at $3 \mathrm{kHz}$, the peak can be related to Brownian relaxation effects [80]. Such a decrease of the ACS signal was previously associated with the immobilization of MNP inside hydrogels [45]. In this case, the relaxation of the MNP is dominated by the Néel relaxation and dipole-dipole interactions strongly influence the MNP relaxation dynamics. Consequently, the classical Debye model of the classical Linear Response Theory [79] used for the description of MNP relaxation dynamics is no longer valid. An extension of this model by considering a distribution of relaxation times, the so-called Cole-Cole model, was proposed to describe 
the relaxation phenomena of MNP inside magnetic scaffolds [41,43]. The ACS results in Figure 6 qualitatively describe the MNP relaxation behavior according to the ColeCole model. In the frequency range used for hyperthermia experiments (approximately $100 \mathrm{kHz}$ and higher), the relative difference between $\chi^{\prime \prime}$ of MNP inside filaments and dispersed MNP is approximately 85\%. Moreover, $\chi^{\prime}$ values of PP@5\%MNP are higher than for PP@3\%MNP and PP@7\%MNP, which seems to relate to the MNP agglomerate size. Further, the smooth decay of $\chi^{\prime}$ values for PP@3\%MNP indicates stronger dipole-dipole interactions [81].
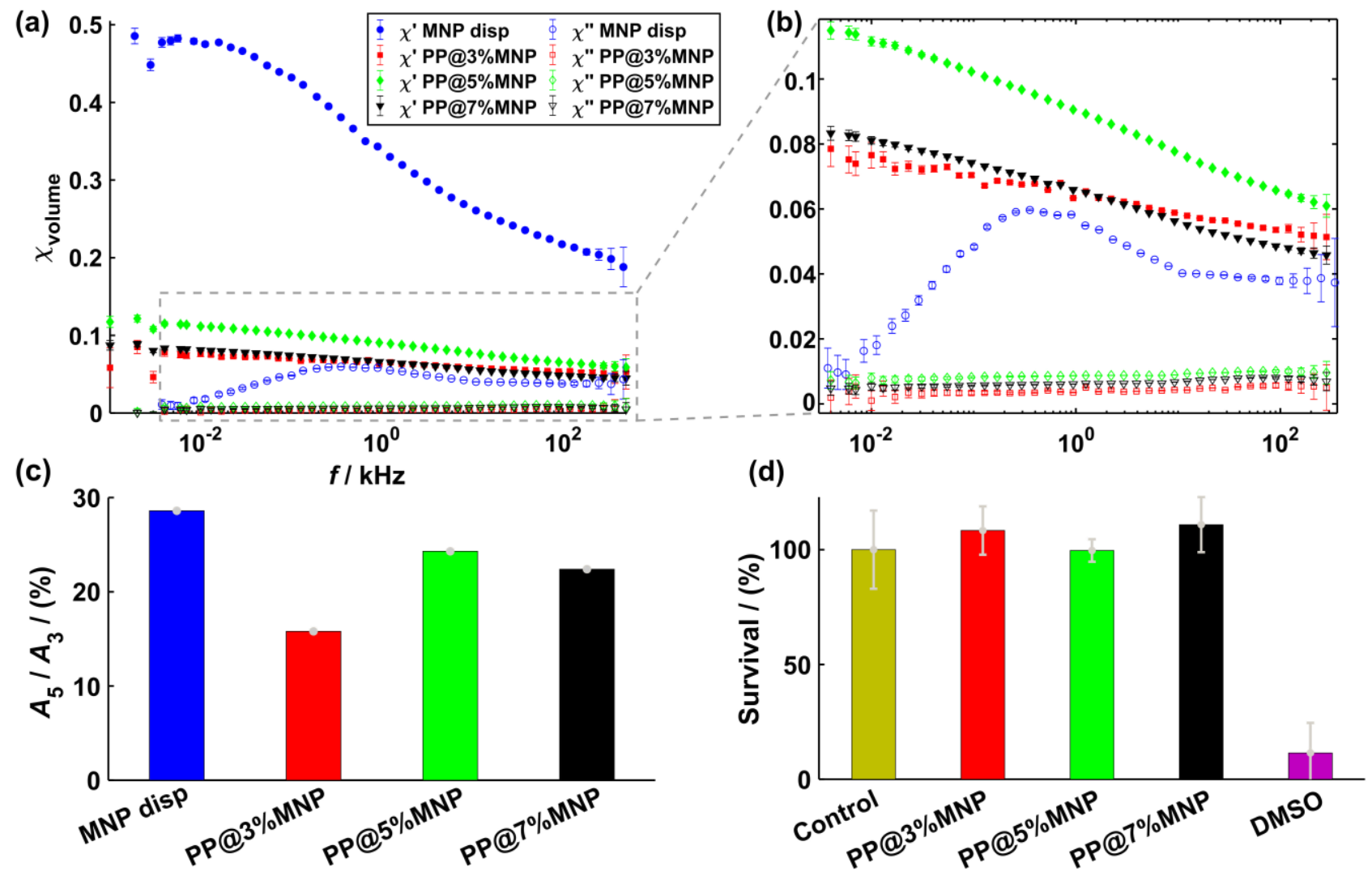

Figure 6. (a) Real part $\chi^{\prime}$ (filled symbols) and imaginary part $\chi^{\prime \prime}$ (open symbols) of the complex dynamic susceptibility for dispersed MNP, MNP inside PP@3\%MNP, PP@5\%MNP, and PP@7\%MNP filaments. (b) Zoom of the volume susceptibility at lower values. (c) $A_{5} / A_{3}$ amplitude ratios for dispersed MNP, MNP inside PP@3\%MNP, PP@5\%MNP, and PP@7\%MNP filaments. (d) Survival analysis of L929 cells after $24 \mathrm{~h}$ incubation with hybrid filaments (PP@3\%MNP, PP@5\%MNP, and PP@7\%MNP).

Figure $6 c$ shows the amplitude ratios $A_{5} / A_{3}$ obtained by MPS for the dispersed MNP and MNP inside the PP filaments, respectively. $A_{5} / A_{3}$ decreases by approximately $45 \%$ for PP@3\%MNP compared to dispersed MNP. For PP@5\%MNP and PP@7\%MNP, a less pronounced decrease of only $15 \%$ and $22 \%$ is observed. Such decrease in $A_{5} / A_{3}$ was recently reported for immobilized particles [37] and for particles agglomerated inside living cells [82]. Furthermore, this trend confirms the presence of stronger dipole-dipole interactions inside PP@3\%MNP filaments as already deduced from the ZFC peak shift (Figure 5b) and susceptibility values (Figure 6a).

Figure $6 \mathrm{~d}$ shows the effects on the cell survival after $24 \mathrm{~h}$ incubation with PP@3\%MNP, PP@5\%MNP, and PP@7\%MNP filaments, respectively. The filaments showed no cytotoxic effect. 


\subsection{Heating Efficiency}

MNP agglomeration and immobilization obviously influences the static and dynamic magnetization behavior of the hybrid filaments. The dipole-dipole interaction and the effective anisotropy energy increase directly influences the non-linear dynamic magnetic susceptibility of the MNP [83]. Since MFH relies on the non-linear dynamic magnetic susceptibility, a significant influence on the heating efficiency is expected. To investigate this, the SLP values of MNP dispersed in water, MNP immobilized in acrylamide hydrogel, PP@3\%MNP, PP@5\%MNP, and PP@7\%MNP are determined. The investigation of MNP immobilized in hydrogels aims at the quantification of the immobilization effect neglecting agglomerations.

In Figure 7a, the SLP results at a magnetic field amplitude of $30 \mathrm{kA} / \mathrm{m}$ with gradual frequency increase from 95 to $270 \mathrm{kHz}$ are shown. The values range from approximately 50 up to $240 \mathrm{~W} / \mathrm{g}_{\mathrm{Fe}}$ and indicate a linear increase with frequency. The SLP dependence of magnetic field amplitude (form approximately 14 to $65 \mathrm{kA} / \mathrm{m}$ ) for three different frequencies $(95,140$, and $270 \mathrm{kHz})$ is shown in Figure $7 \mathrm{~b}-\mathrm{d}$. Overall, the SLP values increase with field amplitude until saturation is reached. The highest SLP value of approximately $300 \mathrm{~W} / \mathrm{g}_{\mathrm{Fe}}$ is reached at the highest frequency $f=270 \mathrm{kHz}$ and field amplitude $H=55 \mathrm{kA} / \mathrm{m}$. In some cases, an "s-shaped" increase of SLP values is observed. This kind of SLP relation to magnetic field amplitude was reported in literature before for magnetosomes immobilized in agarose [84] and explained by the chain structure of magnetosomes accelerating magnetic relaxation. Similarly, certain structures of MNP agglomerates inside the filaments could influence the time-dependent relaxation processes in a magnetic field. SLP saturation effects, however, showing a steep increase with magnetic field amplitude are well known and were reported in literature for different dispersed nanoparticle samples at frequencies ranging from 150 up to $375 \mathrm{kHz}$ [85-87].

In Figure 7, a clear difference in heating efficiency between immobilized MNP and MNP dispersed in water can be observed. This difference is attributed to the blocked Brownian relaxation of MNP. With increasing magnetic field amplitude, the relative SLP difference between dispersed MNP and immobilized MNP (in hydrogel and filaments, respectively) decreases until a certain saturation is reached (at about $30 \mathrm{kA} / \mathrm{m}$ ). Such SLP decrease by up to $35 \%$ at $270 \mathrm{kHz}$ was reported in literature before for $9 \mathrm{~nm}$ iron oxide MNP immobilized in hydrogels [39]. The lowest relative heating efficiency differences between dispersed and immobilized MNP are observed at $270 \mathrm{kHz}$, indicating that at higher frequencies, Néel relaxation dominates. The SLP values of MNP inside hybrid filaments are in most cases lower than those immobilized in hydrogel. These differences can be explained by MNP agglomeration diminishing the heating efficiency and are in agreement with findings from literature [88]. Various sizes of MNP agglomerates may also explain the different SLP values reached for different hybrid filaments. In such cases, the change in the effective anisotropy energy due to dipole-dipole interactions, which is dependent on the MNP agglomerate size (see also magnetization measurements in Figure 5), must be regarded. Monte-Carlo simulations suggest that dipole-dipole interactions lead to significant and complex effects on the energy dissipation rate and that the effects are dependent on intrinsic statistical properties of the MNPs [89]. 
(a)

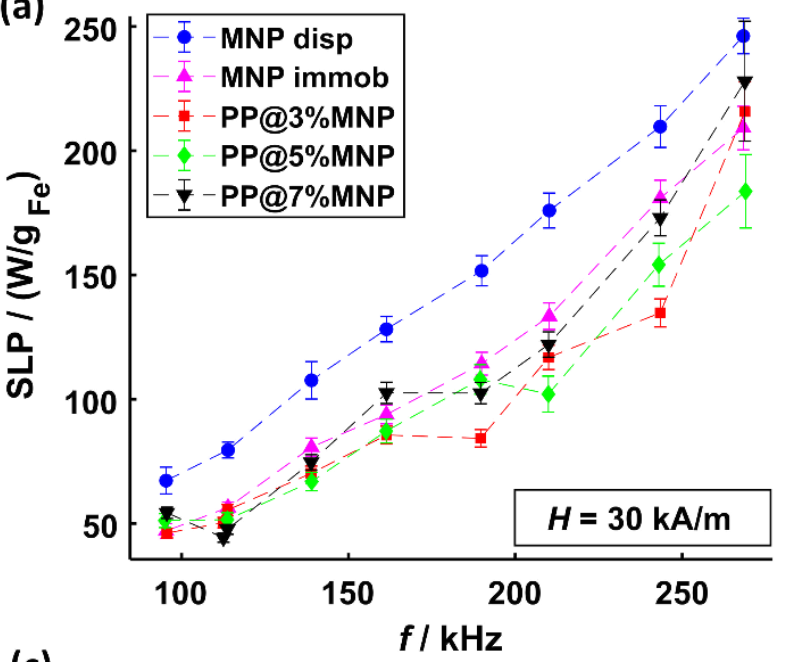

(c)

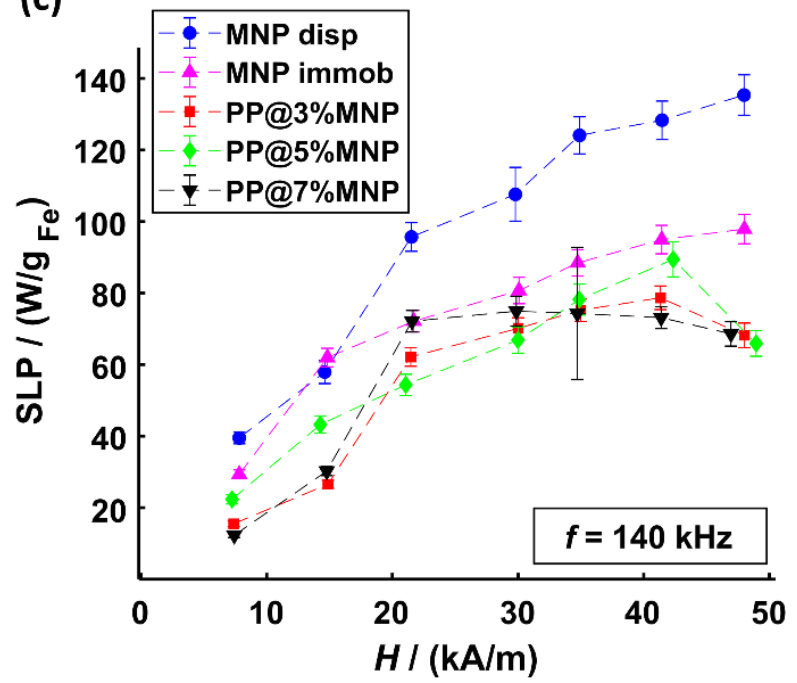

(b)

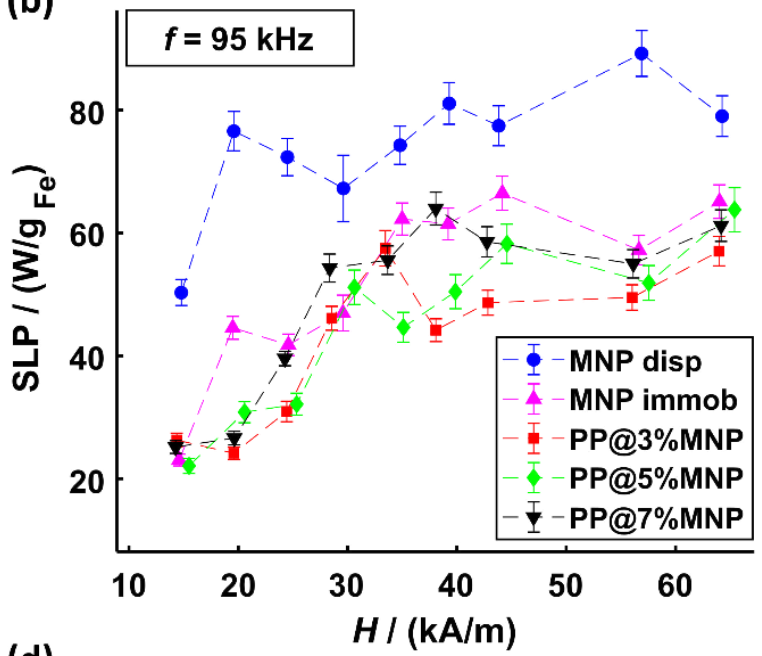

(d)

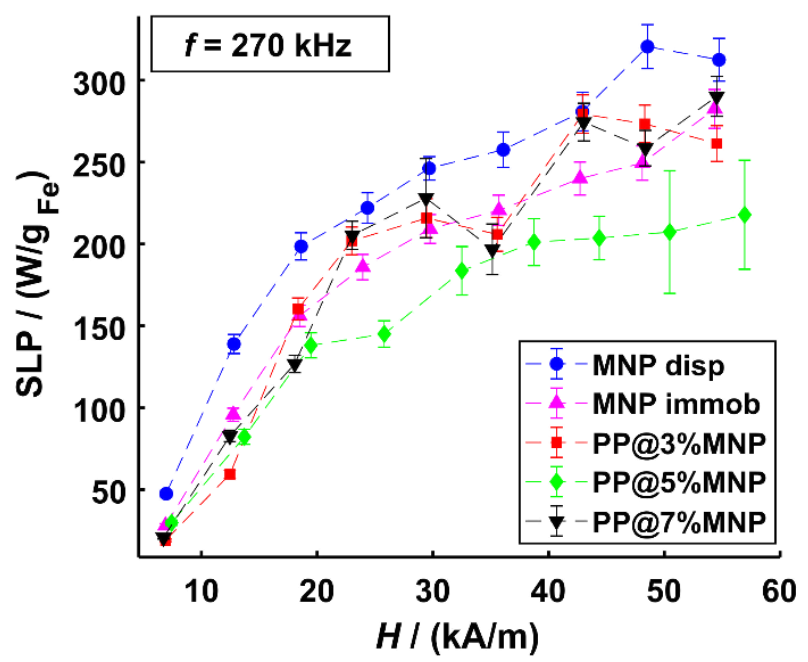

Figure 7. SLP values of MNP dispersed in water and MNP immobilized inside hydrogels as well as inside PP@3\%MNP, PP@5\%MNP, and PP@7\%MNP filaments for (a) different frequencies at a constant magnetic field amplitude of $30 \mathrm{kA} / \mathrm{m}$, (b) different magnetic field amplitudes at $95 \mathrm{kHz}$, (c) different magnetic field amplitudes at $140 \mathrm{kHz}$, and (d) different magnetic field amplitudes at $270 \mathrm{kHz}$.

Such agglomeration and immobilization effects were also observed in the measurements of the imaginary part of the complex dynamic susceptibility $\chi^{\prime \prime}$ (see Figure 6a,b) as well as $A_{5} / A_{3}$ ratio (see Figure 6c) for the same samples. Generally, for MNP agglomerates, the interparticle interactions play an important role leading to either an increase or decrease of SLP depending on MNP's magnetocrystalline properties and the structure of agglomerates. MNP chain formation is associated with an amplified heating efficiency due to long range collective magnetic behavior reducing the magnetostatic energy [84,90]. In contrast, for large and dense centrosymmetric agglomerates, a reduced SLP is often observed and attributed to demagnetization effects, causing a weakened coupling to the external AMF [88,91]. Magnetic moments of MNP inside agglomerates especially at low magnetic field amplitudes increasingly fail to overcome the dipolar field [92]. As recently reported, small Néel dominated MNP immobilized in filaments show especially at small field amplitudes higher heating efficiencies compared to large ferromagnetic MNP clusters of high anisotropy [93]. To overcome the agglomeration driven SLP diminution, other polymers with lower melting temperature, e.g., low-density polyethylene (LDPE), in combination with a temperature resistant particle coating (e.g., silica) can be used to achieve the distribution of individual particles inside the filaments. 


\subsection{Nanomagnetic Actuation of Hybrid Stents}

For hollow organ tumor treatment, the hybrid stents must be able to generate uniformly distributed heat with temperatures of approximately $43{ }^{\circ} \mathrm{C}$ in the surrounding tissue. The feasibility of meeting these demands is demonstrated for three prototype bile duct stents St@3\%MNP, St@5\%MNP, and St@7\%MNP (each $5 \mathrm{~mm} \times 16 \mathrm{~mm}$ ), which are made using PP@3\%MNP, PP@5\%MNP, and PP@7\%MNP filaments, respectively. For this, the temperature rise $\Delta T$ of the stents (at $f=270 \mathrm{kHz}$ and $H=54 \mathrm{kA} / \mathrm{m}$ ) is measured with a thermographic camera placed above the opening of the stents and with a fiber-optic thermometer placed in close vicinity of the stent surface (Figure 8).

(a)

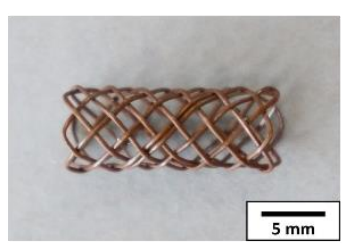

(c)

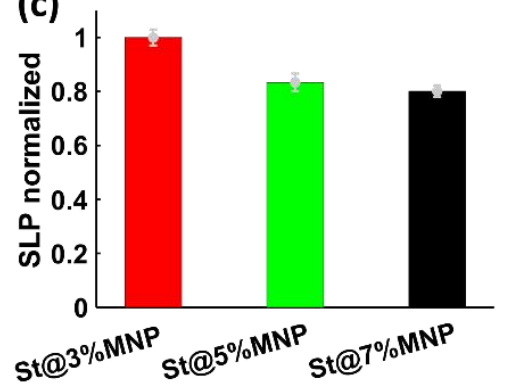

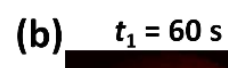
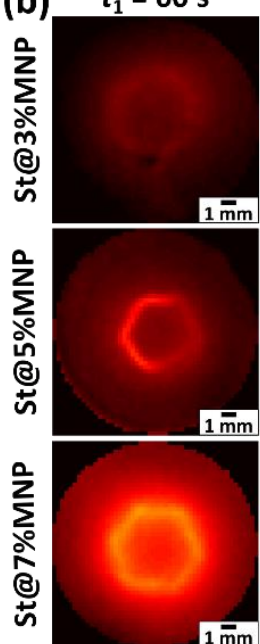

(e)
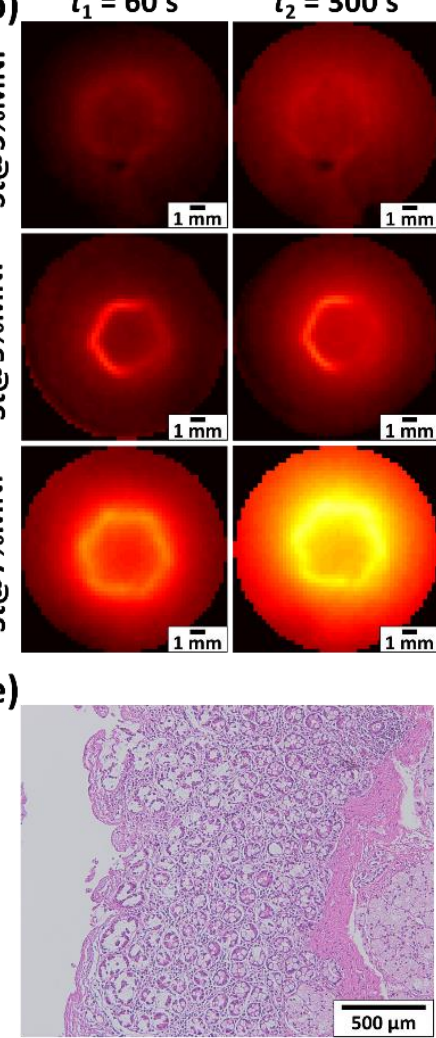

$t_{3}=600 \mathrm{~s}$

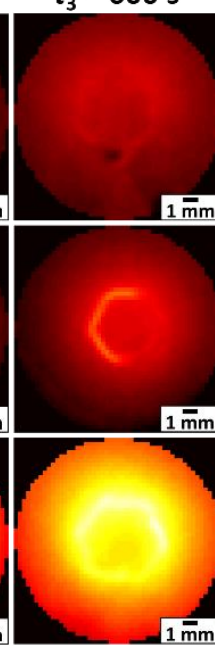

$t_{4}=900 \mathrm{~s}$

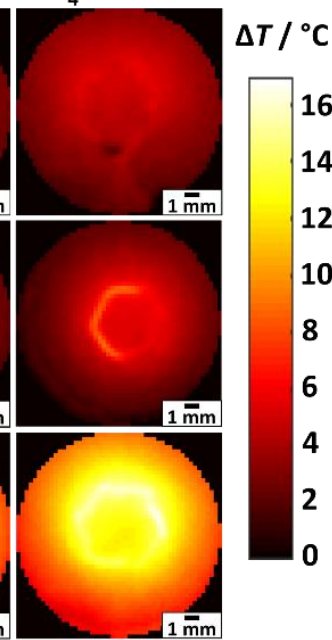

(f)

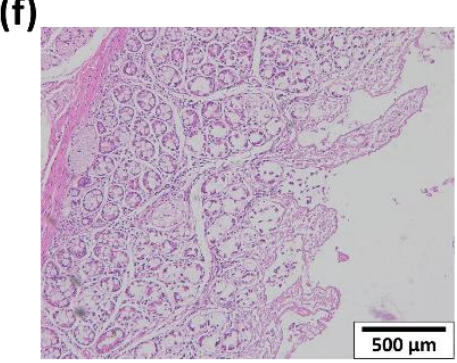

Figure 8. (a) Photograph of an exemplary St@7\%MNP stent. (b) Temperature rise $\Delta T$ of St@3\%MNP, St@5\%MNP, and St@7\%MNP during the application of an AMF with $f=270 \mathrm{kHz}$ and $H=54 \mathrm{kA} / \mathrm{m}$ with a thermographic camera at $t_{1}=60 \mathrm{~s}$, $t_{2}=300 \mathrm{~s}, t_{3}=600 \mathrm{~s}$, and $t_{4}=900 \mathrm{~s}$. (c) Normalized SLP values of St@3\%MNP, St@5\%MNP, and St@7\%MNP (absolute SLP values are provided in Table S6 in Supplemantary Materials S6). (d) Photograph of an exemplary St@5\%MNP stent inserted into a resected bile duct of a pig. The inset shows the temperature distribution during the application of an AFM with $f=270 \mathrm{kHz}$ and $H=38 \mathrm{kA} / \mathrm{m}$. (e) HE staining images of the heated bile duct and (f) an untreated reference bile duct.

Figure 8a shows a picture of an exemplary stent. In Figure $8 \mathrm{~b}$, the temperature rise $\Delta T$ in the surrounding hydrogel at selected AMF exposure times $t_{1}=60 \mathrm{~s}, t_{2}=300 \mathrm{~s}, t_{3}=600 \mathrm{~s}$, and $t_{4}=900 \mathrm{~s}$ is displayed. At $900 \mathrm{~s}$, saturation is reached. The entire heating process up to $t_{\max }=1000 \mathrm{~s}$ was recorded using a thermographic camera and is provided as a video in the Supplementary Materials. $\Delta T$ values of St@3\%MNP, St@5\%MNP, and St@7\%MNP from the thermographic measurements reach values up to 6,9 , and $17^{\circ} \mathrm{C}$, respectively. Based on a body temperature of $37^{\circ} \mathrm{C}$, this corresponds to a heating of the tissue of 43,46 , and $54^{\circ} \mathrm{C}$. Heat uniformly dissipated inside the hydrogel surrounding the stents until an equilibrium was achieved. For all stents, a temperature rise inside the hydrogel up to a distance of approximately $8 \mathrm{~mm}$ to stent surface could be measured. The absolute temperature values strongly depend on the amount of MNP inside the filaments. 
To compare the heating efficiency of the stents, their SLP values were calculated using the $\Delta T$ values after $1000 \mathrm{~s}$. $\Delta T$ was measured with a fiber optical sensor placed in close vicinity to the stent surface. Figure $8 \mathrm{c}$ shows the normalized SLP values resulting from these measurements. Compared to St@3\%MNP, St@5\%MNP and St@7\%MNP have a 16\% and $20 \%$ lower heating efficiency, respectively.

For a first feasibility test of endoscopic stent placement, an exemplary hybrid stent St@5\%MNP was crimped and inserted into the explanted bile duct of a pig. By setting the AMF to $f=270 \mathrm{kHz}$ and $H=38 \mathrm{kA} / \mathrm{m}$, the stent elevated the tissue temperature to $45^{\circ} \mathrm{C}$ at the stent surface for one hour. The thermographic image in Figure $8 \mathrm{~d}$ shows the temperature distribution in the surrounding tissue. The HE staining images of the bile duct tissue after the hyperthermia treatment compared to healthy bile duct tissue (Figure 8e,f) revealed no difference in histology, especially no signs of direct tissue damage.

Nanoactuation of hybrid stents is a promising nanotechnology that enables local hyperthermia treatment with significant advantages over conventional magntic fluid hyperthermia approaches, such as high local MNP concentration. Furthermore, it is easily predictable and allows controllable heat release. The results demonstrate the feasibility of nanomagnetic actuation of three prototype hybrid stents for hyperthermia treatment of hollow organ tumors. Depending on MNP load and field settings, a temperature rise by up to $17^{\circ} \mathrm{C}$ could be achieved. In literature, various temperature rises were reported, such as $20^{\circ} \mathrm{C}$ for gelatin-based scaffolds, $13^{\circ} \mathrm{C}$ for ceramics, or $9{ }^{\circ} \mathrm{C}$ for PCL-based materials $[28,30]$. As previously reported for magnetic scaffolds, the heating perfomence of the hybrid stents is strongly influenced by the change in magnetic relaxation dynamics due to interparticle interactions and blocking of the Brownian relaxation. To describe the relaxation dynamics of MNP in magnetic scaffolds, the Cole-Cole model was proposed [41-43]. Moreover, for a deeper understanding of the fundamentals of the magnetic relaxation processes of MNP and prediction of the heating efficiency of MNP inside hybrid materials, non-equilibrium stochastic simulations of the relaxtions dymanics proved to be a powerful tool $[46,47]$. For clinical applications, safe AMF exposure of the patient must be adhered. The safety limit is defined by the product between field amplitude and frequency $(H \cdot f)_{\text {crit, }}$ which must not exceed a certain critical value. However, several critical values are still under discussion. For clinically available hyperthermia devices, a safety limit of $(H \cdot f)_{\text {crit }}=1.8 \times 10^{9} \mathrm{~A} \cdot \mathrm{m}^{-1} \mathrm{~s}^{-1}$ is considered [32]. FDA guidelines for MRI imaging assume safe values as $(H \cdot f)_{\text {crit }}=3.8 \times 10^{9} \mathrm{~A} \cdot \mathrm{m}^{-1} \mathrm{~s}^{-1}$ [94]. For small body regions and considering the severity of the disease, a higher safety limit of $(H \cdot f)_{\text {crit }}=5 \times 10^{9} \mathrm{~A} \cdot \mathrm{m}^{-1} \mathrm{~s}^{-1}$ is suggested [95]. Even higher values of $(H \cdot f)_{\text {crit }}=6.7 \times 10^{9} \mathrm{~A} \cdot \mathrm{m}^{-1} \mathrm{~s}^{-1}$ were tested and well tolerated in in vivo experiments on mice [96]. For the hybrid stents in this work, the optimization of AMF settings under considerations of safety limits in in vivo trials is envisaged. However, there is an onging discussion about the critical values defining the safety limits. Regulations and standardized protocols for hyperthermia applications have still to be established $[97,98]$. Guidelines for interstitial hyperthermia suggest a target temperature range of 40 to $44^{\circ} \mathrm{C}$ for a period of 30 to 60 min depending on the tumor type. For the clinical translation of the therapeutical approach with nanoactuation of hybrid stents, quality assurance quidelines such as the ones developed for interstitial hyperthermia [99] are necessary. Detailed instructions on characterization and documentation of the performance of hybrid stent induced hyperthermia to achieve reproducible results must be provided. This includes workflow and procedures as well as technical requirements. For this, the development of specific guidelines for intraluminal hyperthermia is recommended.

\section{Conclusions}

In this paper, we describe a magnetic nanotechnology that locally activates hyperthermia treatment of hollow organ tumors. This is enabled by using a polymer hybrid stent with incorporated magnetic nanoparticles (MNP), which is activated in an alternating magnetic field (AMF) to release therapeutically effective heat in a controlled manner. Our investigations demonstrate the feasibility of such nanotechnology for three prototype bile duct 
hybrid stents with three different MNP concentrations (3\%(w/w), 5\%(w/w), and 7\%(w/w)). The stents showed uniformly distributed heat on their surface and inside the surrounding hydrogel as well as inside explanted bile duct of a pig. The parameters controlling heating performance of the hybrid stents such as AMF parameters, MNP immobilization, and agglomeration were thoroughly investigated with different techniques to quantify their impact on heating efficiency. Independent of MNP concentration, the heating efficiency of stent filaments showed an increase with frequency from approximately $60 \mathrm{~W} / \mathrm{g}_{\mathrm{Fe}}$ at $95 \mathrm{kHz}$ to approximately $250 \mathrm{~W} / \mathrm{g}_{\mathrm{Fe}}$ at $270 \mathrm{kHz}$. Further, gradual increase of the magnetic field amplitude resulted in a steep increase in heating efficiency until saturation at approximately $30 \mathrm{kA} / \mathrm{m}$ was reached. The effect of MNP immobilization on heating efficiency was more pronounced at lower frequencies and magnetic field amplitudes, showing a relative difference in heating efficiency of up to $60 \%$ compared to that of freely dispersed MNP. This difference was attributed to the absence of Brownian relaxation to the overall magnetic relaxation process. At higher frequencies and magnetic field amplitudes, such relative difference significantly decreased indicating the domination of Néel relaxation. In most cases, MNP agglomeration showed only a slight decrease in heating efficiency, which was attributed to interparticle interactions. These findings were validated with measurements in static magnetic field (SQUID magnetometry) and dynamic magnetic fields (MPS and AC susceptibility). In conclusion, generation of therapeutically effective temperatures of $43^{\circ} \mathrm{C}$ at the surface of prototype stents, e.g., for the bile duct, with uniformly distributed heat in its surrounding is feasible. This was accomplished by adjusting AMF parameter with regard to MNP properties to control the heating performance. Similar to the results presented in literature for magnetic scaffolds, MNP immobilization and agglomeration effects play an important role in the hyperthermia performance of hybrid stents. Due to the change in MNP effective anisotropy and blocking of Brownian relaxation directly influencing the MNP magnetic relaxation dynamics, the heating efficiency of MNP in the hybrid stents is lower than that of freely dispersed MNP. To enhance the heating efficiency, AFM settings must be adjusted, e.g., higher amplitudes have to be applied. Considering medical safety limits of electromagnetic exposure of the patient, further investigations are necessary to find the best match between AFM settings and MNP properties, to reach the necessary therapeutically effective heat for the lowest possible AFM exposure. As controlling heat release is a complex interplay between field and MNP parameters, models taking into account interparticle interactions, dynamic magnetic relaxation, and anisotropy energy changes of the MNP are necessary for the accurate prediction of the heat performance of hybrid stents. First investigations demonstrated the biological safety of the hybrid stents. The investigation of therapeutical effects of the hybrid stent hyperthermia treatment are envisaged.

Supplementary Materials: The following Supplementary Materials are available online at https:// www.mdpi.com/2079-4991/11/3/618/s1: Table S2, Figure S2, Figure S3, Table S4, Figure S5, Table S6 and thermal videos of the entire heating process of stents: “Temperature_distribution_St@3\%MNP", “Temperature_distribution_St@5\%MNP" and “Temperature_distribution_St@7\%MNP".

Author Contributions: B.M. and I.S. conceived and designed the experiments. I.S. supervised the research activity. B.M. synthesized MNP and the acrylamide hydrogel and performed PA, DLS, XRD, and hyperthermia measurements. I.S. performed the magnetic measurements. B.B. produced the hybrid filaments. J.O. performed TGA measurements. E.M.B. performed TEM measurements. P.R. performed MPS and ACS measurements. A.A.R. performed the cytotoxicity tests and H\&E staining. B.M. and I.S. analyzed all data, prepared the Figures, and wrote the manuscript. F.W., T.G., and T.S.-R. proofread the manuscript and improved the quality of the manuscript. All authors were involved in the discussion and interpretation of the results. All authors have read and agreed to the published version of the manuscript.

Funding: This research project was funded as part of the program "Joint Industrial Research (IGF)" of the German Federal Ministry of Economic Affairs and Energy (contract number: 19735 N). 
Institutional Review Board Statement: The study was conducted according to the guidelines of the Declaration of Helsinki. The animal cadaver was taken from other approved animal experiments directly after euthanization. No additional ethical approval was needed according to German law and in agreement with the LANUV (State Agency for Nature, Environment, and Consumer Protection, North Rhine-Westphalia).

Informed Consent Statement: Not applicable.

Data Availability Statement: The data that support the findings of this study are available from the corresponding author, I.S., upon reasonable request.

Acknowledgments: We thank Max Leo Leidl and Alexander Hohle for assistance with hyperthermia experiments and Katja Goltz for support for the cytotoxicity tests.

Conflicts of Interest: The authors declare no conflict of interest.

\section{References}

1. $\quad$ Bakheet, N.; Park, J.-H.; Hu, H.-T.; Yoon, S.H.; Kim, K.Y.; Zhe, W.; Jeon, J.Y.; Song, H.-Y. Fully Covered Self-Expandable Esophageal Metallic Stents in Patients with Inoperable Malignant Disease Who Survived for More than 6 Months after Stent Placement. BJR 2019, 92, 20190321. [CrossRef]

2. Gupta, A.; Gupta, G.; Gawande, A.; Kumar, M.; Tak, V.; Pokharna, R.; Sharma, S.; Nijhawan, S. Self-Expanding Metallic Stents in Malignant Biliary Obstruction-Patency and Clinical Efficacy: A Prospective Study from North India Tertiary Center. J. Dig. Endosc. 2019, 10, 33-38. [CrossRef]

3. Maire, F.; Hammel, P.; Ponsot, P.; Aubert, A.; O’Toole, D.; Hentic, O.; Levy, P.; Ruszniewski, P. Long-Term Outcome of Biliary and Duodenal Stents in Palliative Treatment of Patients with Unresectable Adenocarcinoma of the Head of Pancreas. Am. J. Gastroenterol. 2006, 101, 735-742. [CrossRef]

4. Wasan, S.M.; Ross, W.A.; Staerkel, G.A.; Lee, J.H. Use of Expandable Metallic Biliary Stents in Resectable Pancreatic Cancer. Am. J. Gastroenterol. 2005, 100, 2056-2061. [CrossRef]

5. Zhu, H.-D.; Guo, J.-H.; Mao, A.-W.; Lv, W.-F.; Ji, J.-S.; Wang, W.-H.; Lv, B.; Yang, R.-M.; Wu, W.; Ni, C.-F.; et al. Conventional Stents versus Stents Loaded with 125iodine Seeds for the Treatment of Unresectable Oesophageal Cancer: A Multicentre, Randomised Phase 3 Trial. Lancet Oncol. 2014, 15, 612-619. [CrossRef]

6. Pu, L.Z.C.T.; Singh, R.; Loong, C.K.; de Moura, E.G.H. Malignant Biliary Obstruction: Evidence for Best Practice. Gastroenterol. Res. Pract. 2016, 2016, 1-7. [CrossRef]

7. Xie, X.; Zheng, X.; Han, Z.; Chen, Y.; Zheng, Z.; Zheng, B.; He, X.; Wang, Y.; Kaplan, D.L.; Li, Y.; et al. A Biodegradable Stent with Surface Functionalization of Combined-Therapy Drugs for Colorectal Cancer. Adv. Healthc. Mater. 2018, 7, 1801213. [CrossRef] [PubMed]

8. Saranovic, D.; Djuric-Stefanovic, A.; Ivanovic, A.; Masulovic, D.; Pesko, P. Fluoroscopically Guided Insertion of Self-Expandable Metal Esophageal Stents for Palliative Treatment of Patients with Malignant Stenosis of Esophagus and Cardia: Comparison of Uncovered and Covered Stent Types. Dis. Esophagus 2005, 18, 230-238. [CrossRef] [PubMed]

9. Etemadi, H.; Plieger, P.G. Magnetic Fluid Hyperthermia Based on Magnetic Nanoparticles: Physical Characteristics, Historical Perspective, Clinical Trials, Technological Challenges, and Recent Advances. Adv. Therap. 2020, 3, 2000061. [CrossRef]

10. Salimi, M.; Sarkar, S.; Hashemi, M.; Saber, R. Treatment of Breast Cancer-Bearing BALB/c Mice with Magnetic Hyperthermia Using Dendrimer Functionalized Iron-Oxide Nanoparticles. Nanomaterials 2020, 10, 2310. [CrossRef]

11. Nemec, S.; Kralj, S.; Wilhelm, C.; Abou-Hassan, A.; Rols, M.-P.; Kolosnjaj-Tabi, J. Comparison of Iron Oxide Nanoparticles in Photothermia and Magnetic Hyperthermia: Effects of Clustering and Silica Encapsulation on Nanoparticles' Heating Yield. Appl. Sci. 2020, 10, 7322. [CrossRef]

12. Plan Sangnier, A.; Preveral, S.; Curcio, A.; Silva, A.K.; Lefèvre, C.T.; Pignol, D.; Lalatonne, Y.; Wilhelm, C. Targeted Thermal Therapy with Genetically Engineered Magnetite Magnetosomes@RGD: Photothermia Is Far More Efficient than Magnetic Hyperthermia. J. Control. Release 2018, 279, 271-281. [CrossRef] [PubMed]

13. Brero, F.; Albino, M.; Antoccia, A.; Arosio, P.; Avolio, M.; Berardinelli, F.; Bettega, D.; Calzolari, P.; Ciocca, M.; Corti, M.; et al. Hadron Therapy, Magnetic Nanoparticles and Hyperthermia: A Promising Combined Tool for Pancreatic Cancer Treatment. Nanomaterials 2020, 10, 1919. [CrossRef] [PubMed]

14. Pan, J.; Hu, P.; Guo, Y.; Hao, J.; Ni, D.; Xu, Y.; Bao, Q.; Yao, H.; Wei, C.; Wu, Q.; et al. Combined Magnetic Hyperthermia and Immune Therapy for Primary and Metastatic Tumor Treatments. ACS Nano 2020, 14, 1033-1044. [CrossRef] [PubMed]

15. El-Dessouky, H.M.; Lawrence, C.A. Nanoparticles Dispersion in Processing Functionalised PP/TiO2 Nanocomposites: Distribution and Properties. J. Nanopart. Res. 2011, 13, 1115-1124. [CrossRef]

16. Delgado, K.; Quijada, R.; Palma, R.; Palza, H. Polypropylene with Embedded Copper Metal or Copper Oxide Nanoparticles as a Novel Plastic Antimicrobial Agent: Novel Antimicrobial Plastic Materials. Lett. Appl. Microbiol. 2011, 53, 50-54. [CrossRef]

17. Baumann, M.; Mahnken, A.; Floren, M.; Günther, R.; Müller-Schulte, D.; Schmitz-Rode, T. Erste In-vitro-Anwendung katheterund magnetgesteuerter ferromagnetischer Polymerfilamente aus Nanopartikeln mit hitzeinduzierter Partikelabgabe unter Einsatz des Stereotaxis-Niobe ${ }^{\circledR}$-Systems. RöFo Fortschr. Ront. 2006, 178, 911-917. [CrossRef] 
18. Slabu, I.; Wirch, N.; Caumanns, T.; Theissmann, R.; Krüger, M.; Schmitz-Rode, T.; Weirich, T.E. Electron Tomography and Nano-Diffraction Enabling the Investigation of Individual Magnetic Nanoparticles inside Fibers of MR Visible Implants. J. Phys. D: Appl. Phys. 2017, 50, 315303. [CrossRef]

19. Zhou, S.; Yang, R.; Zou, Q.; Zhang, K.; Yin, T.; Zhao, W.; Shapter, J.G.; Gao, G.; Fu, Q. Fabrication of Tissue-Engineered Bionic Urethra Using Cell Sheet Technology and Labeling By Ultrasmall Superparamagnetic Iron Oxide for Full-Thickness Urethral Reconstruction. Theranostics 2017, 7, 2509-2523. [CrossRef]

20. Mertens, M.E.; Koch, S.; Schuster, P.; Wehner, J.; Wu, Z.; Gremse, F.; Schulz, V.; Rongen, L.; Wolf, F.; Frese, J.; et al. USPIO-Labeled Textile Materials for Non-Invasive MR Imaging of Tissue-Engineered Vascular Grafts. Biomaterials 2015, 39, 155-163. [CrossRef]

21. Liu, Z.; Zhu, S.; Liu, L.; Ge, J.; Huang, L.; Sun, Z.; Zeng, W.; Huang, J.; Luo, Z. A Magnetically Responsive Nanocomposite Scaffold Combined with Schwann Cells Promotes Sciatic Nerve Regeneration upon Exposure to Magnetic Field. Int. J. Nanomed. 2017, 12, 7815-7832. [CrossRef] [PubMed]

22. Zhang, H.; Xia, J.; Pang, X.; Zhao, M.; Wang, B.; Yang, L.; Wan, H.; Wu, J.; Fu, S. Magnetic Nanoparticle-Loaded Electrospun Polymeric Nanofibers for Tissue Engineering. Mater. Sci. Eng. C 2017, 73, 537-543. [CrossRef] [PubMed]

23. Dang, C.; Bhattarai, N.; Edmondson, D.; Cooper, A.; Zhang, M. Aligning Poly(L-Lactic Acid) Nanofibers with Magnetic Fe3O4 Nanoparticles Using Modified Electrospinning Methods. J. Undergrad. Res. Bioeng. 2009, 5, 29-32.

24. Niiyama, E.; Uto, K.; Lee, C.M.; Sakura, K.; Ebara, M. Hyperthermia Nanofiber Platform Synergized by Sustained Release of Paclitaxel to Improve Antitumor Efficiency. Adv. Healthc. Mater. 2019, 8, 1900102. [CrossRef] [PubMed]

25. Darwish, M.S.A.; Bakry, A.; Kolek, O.; Martinová, L.; Stibor, I. Electrospun Functionalized Magnetic Polyamide 6 Composite Nanofiber: Fabrication and Stabilization. Polym. Compos. 2019, 40, 296-303. [CrossRef]

26. Aguilar, M.R.; San Román, J. Introduction to Smart Polymers and Their Applications. In Smart Polymers and Their Applications; Elsevier: Amsterdam, The Netherlands, 2019; pp. 1-11. ISBN 978-0-08-102416-4.

27. Zhong, Y.; Leung, V.; Yuqin Wan, L.; Dutz, S.; Ko, F.K.; Häfeli, U.O. Electrospun Magnetic Nanofibre Mats - A New Bondable Biomaterial Using Remotely Activated Magnetic Heating. J. Magn. Magn. Mater. 2015, 380, 330-334. [CrossRef]

28. Bañobre-López, M.; Piñeiro-Redondo, Y.; Sandri, M.; Tampieri, A.; Santis, R.D.; Dediu, V.A.; Rivas, J. Hyperthermia Induced in Magnetic Scaffolds for Bone Tissue Engineering. IEEE Trans. Magn. 2014, 50, 5400507. [CrossRef]

29. Dong, S.; Chen, Y.; Yu, L.; Lin, K.; Wang, X. Magnetic Hyperthermia-Synergistic H2O2 Self-Sufficient Catalytic Suppression of Osteosarcoma with Enhanced Bone-Regeneration Bioactivity by 3D-Printing Composite Scaffolds. Adv. Funct. Mater. 2020, 15, 1907071. [CrossRef]

30. Ikenaga, M.; Ohura, K.; Yamamuro, T.; Kotoura, Y.; Oka, M.; Kokubo, T. Localized Hyperthermic Treatment of Experimental Bone Tumors with Ferromagnetic Ceramics. J. Orthop. Res. 1993, 11, 849-855. [CrossRef]

31. Li, G.; Zhang, K.; Pei, Z.; Zhang, N.; Yu, Y.; Zhao, S.; Liang, G.; Zhou, J.; Xing, Y. A Novel Method to Enhance Magnetic Property of Bioactive Glass-Ceramics for Hyperthermia. Ceram. Int. 2019, 45, 4945-4956. [CrossRef]

32. Thiesen, B.; Jordan, A. Clinical Applications of Magnetic Nanoparticles for Hyperthermia. Int. J. Hyperthermia 2008, 24, 467-474. [CrossRef]

33. Liu, J.F.; Jang, B.; Issadore, D.; Tsourkas, A. Use of Magnetic Fields and Nanoparticles to Trigger Drug Release and Improve Tumor Targeting. WIREs Nanomed. Nanobiotechnol. 2019, 11, 1571. [CrossRef]

34. Slabu, I.; Roeth, A.A.; Engelmann, U.M.; Wiekhorst, F.; Buhl, E.M.; Neumann, U.P.; Schmitz-Rode, T. Modeling of Magnetoliposome Uptake in Human Pancreatic Tumor Cells in Vitro. Nanotechnology 2019, 30, 184004. [CrossRef]

35. Engelmann, U.M.; Roeth, A.A.; Eberbeck, D.; Buhl, E.M.; Neumann, U.P.; Schmitz-Rode, T.; Slabu, I. Combining Bulk Temperature and Nanoheating Enables Advanced Magnetic Fluid Hyperthermia Efficacy on Pancreatic Tumor Cells. Sci. Rep. 2018, 8, 13210. [CrossRef] [PubMed]

36. Ng, E.Y.K.; Kumar, S.D. Physical Mechanism and Modeling of Heat Generation and Transfer in Magnetic Fluid Hyperthermia through Néelian and Brownian Relaxation: A Review. BioMed. Eng. OnLine 2017, 16, 36. [CrossRef]

37. Engelmann, U.M.; Buhl, E.M.; Draack, S.; Viereck, T.; Ludwig, F.; Schmitz-Rode, T.; Slabu, I. Magnetic Relaxation Study of Agglomerated and Immobilized Magnetic Iron-Oxide Nanoparticles for Hyperthermia and Imaging Applications. IEEE Magn. Lett. 2016, 7, 1-5. [CrossRef]

38. Engelmann, U.; Buhl, E.M.; Baumann, M.; Schmitz-Rode, T.; Slabu, I. Agglomeration of Magnetic Nanoparticles and Its Effects on Magnetic Hyperthermia. Curr. Dir. Biomed. Eng. 2017, 3, 457-460. [CrossRef]

39. Engelmann, U.M.; Seifert, J.; Mues, B.; Roitsch, S.; Ménager, C.; Schmidt, A.M.; Slabu, I. Heating Efficiency of Magnetic Nanoparticles Decreases with Gradual Immobilization in Hydrogels. J. Magn. Magn. Mater. 2019, 471, 486-494. [CrossRef]

40. Carrey, J.; Mehdaoui, B.; Respaud, M. Simple Models for Dynamic Hysteresis Loop Calculations of Magnetic Single-Domain Nanoparticles: Application to Magnetic Hyperthermia Optimization. J. Appl. Phys. 2011, 109, 083921. [CrossRef]

41. Fanti, A.; Lodi, M.B.; Mazzarella, G. Enhancement of Cell Migration Rate Toward a Superparamagnetic Scaffold Using LF Magnetic Fields. IEEE Trans. Magn. 2016, 52, 5200508. [CrossRef]

42. Landi, G.T.; Arantes, F.R.; Cornejo, D.R.; Bakuzis, A.F.; Andreu, I.; Natividad, E. AC Susceptibility as a Tool to Probe the Dipolar Interaction in Magnetic Nanoparticles. J. Magn. Magn. Mater. 2017, 421, 138-151. [CrossRef]

43. Lodi, M.B.; Fanti, A.; Muntoni, G.; Mazzarella, G. A Multiphysic Model for the Hyperthermia Treatment of Residual Osteosarcoma Cells in Upper Limbs Using Magnetic Scaffolds. IEEE J. Multiscale Multiphys. Comput. Tech. 2019, 4, 337-347. [CrossRef] 
44. Fanti, A.; Lodi, M.B.; Vacca, G.; Mazzarella, G. Numerical Investigation of Bone Tumor Hyperthermia Treatment Using Magnetic Scaffolds. IEEE J. Electromagn., RF, Microw. Med. Biol. 2018, 2, 294-301. [CrossRef]

45. van Berkum, S.; Dee, J.T.; Philipse, A.P.; Erné, B.H. Frequency-Dependent Magnetic Susceptibility of Magnetite and Cobalt Ferrite Nanoparticles Embedded in PAA Hydrogel. Int. J. Mol. Sci. 2013, 14, 10162-10177. [CrossRef]

46. Shasha, C.; Krishnan, K.M. Nonequilibrium Dynamics of Magnetic Nanoparticles with Applications in Biomedicine. Adv. Mater. 2020, 1904131. [CrossRef] [PubMed]

47. Engelmann, U.M.; Shasha, C.; Teeman, E.; Slabu, I.; Krishnan, K.M. Predicting Size-Dependent Heating Efficiency of Magnetic Nanoparticles from Experiment and Stochastic Néel-Brown Langevin Simulation. J. Magn. Magn. Mater. 2019, 471, 450-456. [CrossRef]

48. Usov, N.A.; Rytov, R.A.; Bautin, V.A. Dynamics of Superparamagnetic Nanoparticle in Viscous Liquid in Rotating Magnetic Field. Beilstein J. Nanotechnol. 2019, 10, 2294-2303. [CrossRef] [PubMed]

49. Dennis, C.L.; Ivkov, R. Physics of Heat Generation Using Magnetic Nanoparticles for Hyperthermia. Int. J. Hyperthermia 2013, 29, 715-729. [CrossRef]

50. Kafrouni, L.; Savadogo, O. Recent Progress on Magnetic Nanoparticles for Magnetic Hyperthermia. Prog. Biomater. 2016, 5, 147-160. [CrossRef]

51. Thanh, N.T. Magnetic Nanoparticles: From Fabrication to Clinical Applications; CRC Press: Boca Raton, FL, USA, 2012; pp. 452-454. ISBN 1-4398-6932-4.

52. Floren, M.G.; Günther, R.W.; Schmitz-Rode, T. Noninvasive Inductive Stent Heating: Alternative Approach to Prevent Instent Restenosis? Invest. Radiol. 2004, 39, 264-270. [CrossRef]

53. Li, L.; Wang, R.; Shi, H.-H.; Xie, L.; Li, J.-D.-S.; Kong, W.-C.; Tang, J.-T.; Ke, D.-N.; Zhao, L.-Y. In Vitro Study on the Feasibility of Magnetic Stent Hyperthermia for the Treatment of Cardiovascular Restenosis. Exp. Ther. Med. 2013, 6, 347-354. [CrossRef]

54. Khalafalla, S.; Reimers, G. Preparation of Dilution-Stable Aqueous Magnetic Fluids. IEEE Trans. Magn. 1980, 16, 178-183. [CrossRef]

55. Mark, J.E. Polymer Data Handbook; Oxford University Press: New York, NY, USA, 1998; pp. $247-251$.

56. Sánchez-Bajo, F.; Cumbrera, F.L. The Use of the Pseudo-Voigt Function in the Variance Method of X-Ray Line-Broadening Analysis. J. Appl. Crystallogr. 1997, 30, 427-430. [CrossRef]

57. Langford, J.I.; Wilson, A.J.C. Scherrer after Sixty Years: A Survey and Some New Results in the Determination of Crystallite Size. J. Appl. Crystallogr. 1978, 11, 102-113. [CrossRef]

58. Bhadani, S.N.; Tiwari, M.; Agrawal, A.; Kavipurapu, C.S. Spectrophotometric Determination of Fe(III) with Tiron in the Presence of Cationic Surfactant and Its Application for the Determination of Iron in Al-Alloys and Cu-Based Alloys. Mikrochim. Acta 1994, 117, 15-22. [CrossRef]

59. Cannella, V.; Altomare, R.; Leonardi, V.; Russotto, L.; Di Bella, S.; Mira, F.; Guercio, A. In Vitro Biocompatibility Evaluation of Nine Dermal Fillers on L929 Cell Line. BioMed Res. Int. 2020, 2020, 1-6. [CrossRef]

60. Ozdemir, K.G.; Yılmaz, H.; Yılmaz, S. In Vitro Evaluation of Cytotoxicity of Soft Lining Materials on L929 Cells by MTT Assay. J. Biomed. Mater. Res. 2008, 90B, 82-86. [CrossRef] [PubMed]

61. Bernard, M.; Jubeli, E.; Bakar, J.; Tortolano, L.; Saunier, J.; Yagoubi, N. Biocompatibility Assessment of Cyclic Olefin Copolymers: Impact of Two Additives on Cytotoxicity, Oxidative Stress, Inflammatory Reactions, and Hemocompatibility: Biocompatibility Assessment of Coc. J. Biomed. Mater. Res. 2017, 105, 3333-3349. [CrossRef]

62. Krämer, M.; Schilling, M.; Eifler, R.; Hering, B.; Reifenrath, J.; Besdo, S.; Windhagen, H.; Willbold, E.; Weizbauer, A. Corrosion Behavior, Biocompatibility and Biomechanical Stability of a Prototype Magnesium-Based Biodegradable Intramedullary Nailing System. Mater. Sci. Eng. C 2016, 59, 129-135. [CrossRef] [PubMed]

63. Lickorish, D.; Ramshaw, J.A.M.; Werkmeister, J.A.; Glattauer, V.; Howlett, C.R. Collagen-Hydroxyapatite Composite Prepared by Biomimetic Process. J. Biomed. Mater. Res. 2004, 68A, 19-27. [CrossRef]

64. Chen, S.; Yu, L.; Zhao, Q.; Ren, Y.; Guo, L.; Gong, X.; Wan, X.; Yuan, G.; Li, B. Comparative Assessment of the Biocompatibility and Degradation Behavior of Zn-3Cu and JDBM Alloys Used for Biliary Surgery. Am. J. Transl. Rese. 2020, 12, 19-31.

65. Chantrell, R.; Popplewell, J.; Charles, S. Measurements of Particle Size Distribution Parameters in Ferrofluids. IEEE Trans. Magn. 1978, 14, 975-977. [CrossRef]

66. O'grady, K.; Bradbury, A. Particle Size Analysis in Ferrofluids. J. Magn. Magn. Mater. 1983, 39, 91-94. [CrossRef]

67. Ludwig, F.; Remmer, H.; Kuhlmann, C.; Wawrzik, T.; Arami, H.; Ferguson, R.M.; Krishnan, K.M. Self-Consistent Magnetic Properties of Magnetite Tracers Optimized for Magnetic Particle Imaging Measured by Ac Susceptometry, Magnetorelaxometry and Magnetic Particle Spectroscopy. J. Magn. Magn. Mater. 2014, 360, 169-173. [CrossRef]

68. Wu, K.; Su, D.; Saha, R.; Liu, J.; Chugh, V.K.; Wang, J.-P. Magnetic Particle Spectroscopy: A Short Review of Applications Using Magnetic Nanoparticles. ACS Appl. Nano Mater. 2020, 3, 4972-4989. [CrossRef]

69. Wildeboer, R.R.; Southern, P.; Pankhurst, Q.A. On the Reliable Measurement of Specific Absorption Rates and Intrinsic Loss Parameters in Magnetic Hyperthermia Materials. J. Phys. D Appl. Phys. 2014, 47, 495003. [CrossRef]

70. Makridis, A.; Curto, S.; van Rhoon, G.C.; Samaras, T.; Angelakeris, M. A Standardisation Protocol for Accurate Evaluation of Specific Loss Power in Magnetic Hyperthermia. J. Phys. D Appl. Phys. 2019, 52, 255001. [CrossRef] 
71. Prashantha, K.; Soulestin, J.; Lacrampe, M.F.; Claes, M.; Dupin, G.; Krawczak, P. Multi-Walled Carbon Nanotube Filled Polypropylene Nanocomposites Based on Masterbatch Route: Improvement of Dispersion and Mechanical Properties through PP-g-MA Addition. Express Polym. Lett. 2008, 2, 735-745. [CrossRef]

72. Rehman, M.; Madni, A.; Khan, W.S.; Ihsan, A.; Khan, M.I.; Mahmood, M.A.; Ashfaq, M.; Bajwa, S.Z.; Shakir, I. Solid and Liquid Lipid-Based Binary Solid Lipid Nanoparticles of Diacerein: In Vitro Evaluation of Sustained Release, Simultaneous Loading of Gold Nanoparticles, and Potential Thermoresponsive Behavior. Int. J. Nanomed. 2015, 10, 2805-2814. [CrossRef] [PubMed]

73. Ludwig, F.; Wawrzik, T.; Yoshida, T.; Gehrke, N.; Briel, A.; Eberbeck, D.; Schilling, M. Optimization of Magnetic Nanoparticles for Magnetic Particle Imaging. IEEE Trans. Magn. 2012, 48, 3780-3783. [CrossRef]

74. Ota, S.; Yamada, T.; Takemura, Y. Magnetization Reversal and Specific Loss Power of Magnetic Nanoparticles in Cellular Environment Evaluated by AC Hysteresis Measurement. J. Nanomater. 2015, 2015, 1-8. [CrossRef]

75. Kostopoulou, A.; Lappas, A. Colloidal Magnetic Nanocrystal Clusters: Variable Length-Scale Interaction Mechanisms, Synergetic Functionalities and Technological Advantages. Nanotechnol. Rev. 2015, 4. [CrossRef]

76. Tournus, F.; Tamion, A. Magnetic Susceptibility Curves of a Nanoparticle Assembly II. Simulation and Analysis of ZFC/FC Curves in the Case of a Magnetic Anisotropy Energy Distribution. J. Magn. Magn. Mater. 2011, 323, 1118-1127. [CrossRef]

77. Saville, S.L.; Qi, B.; Baker, J.; Stone, R.; Camley, R.E.; Livesey, K.L.; Ye, L.; Crawford, T.M.; Thompson Mefford, O. The Formation of Linear Aggregates in Magnetic Hyperthermia: Implications on Specific Absorption Rate and Magnetic Anisotropy. J. Colloid Interface Sci. 2014, 424, 141-151. [CrossRef] [PubMed]

78. Wang, C.; Hsu, C.-H.; Li, Z.; Hwang, L.-P.; Lin, Y.-C.; Chou, P.-T.; Lin, Y.-Y. Effective Heating of Magnetic Nanoparticle Aggregates for in Vivo Nano-Theranostic Hyperthermia. Int. J. Nanomed. 2017, 12, 6273-6287. [CrossRef] [PubMed]

79. Rosensweig, R.E. Heating Magnetic Fluid with Alternating Magnetic Field. J. Magn. Magn. Mater. 2002, 252, 370-374. [CrossRef]

80. Maldonado-Camargo, L.; Torres-Díaz, I.; Chiu-Lam, A.; Hernández, M.; Rinaldi, C. Estimating the Contribution of Brownian and Néel Relaxation in a Magnetic Fluid through Dynamic Magnetic Susceptibility Measurements. J. Magn. Magn. Mater. 2016, 412, 223-233. [CrossRef]

81. Cabrera, D.; Coene, A.; Leliaert, J.; Artés-Ibáñez, E.J.; Dupré, L.; Telling, N.D.; Teran, F.J. Dynamical Magnetic Response of Iron Oxide Nanoparticles Inside Live Cells. ACS Nano 2018, 12, 2741-2752. [CrossRef]

82. Ficko, B.W.; NDong, C.; Giacometti, P.; Griswold, K.E.; Diamond, S.G. A Feasibility Study of Nonlinear Spectroscopic Measurement of Magnetic Nanoparticles Targeted to Cancer Cells. IEEE Trans. Biomed. Eng. 2017, 64, 972-979. [CrossRef]

83. Das, R.; Kim, N.P.; Attanayake, S.B.; Phan, M.-H.; Srikanth, H. Role of Magnetic Anisotropy on the Hyperthermia Efficiency in Spherical Fe3-XCoxO4 (x = 0-1) Nanoparticles. Appl. Sci. 2021, 11, 930. [CrossRef]

84. Muela, A.; Muñoz, D.; Martín-Rodríguez, R.; Orue, I.; Garaio, E.; Abad Díaz de Cerio, A.; Alonso, J.; García, J.Á.; FdezGubieda, M.L. Optimal Parameters for Hyperthermia Treatment Using Biomineralized Magnetite Nanoparticles: Theoretical and Experimental Approach. J. Phys. Chem. C 2016, 120, 24437-24448. [CrossRef]

85. Soetaert, F.; Kandala, S.K.; Bakuzis, A.; Ivkov, R. Experimental Estimation and Analysis of Variance of the Measured Loss Power of Magnetic Nanoparticles. Sci. Rep. 2017, 7, 6661. [CrossRef]

86. Bordelon, D.E.; Cornejo, C.; Grüttner, C.; Westphal, F.; DeWeese, T.L.; Ivkov, R. Magnetic Nanoparticle Heating Efficiency Reveals Magneto-Structural Differences When Characterized with Wide Ranging and High Amplitude Alternating Magnetic Fields. J. Appl. Phys. 2011, 109, 124904. [CrossRef]

87. Dennis, C.L.; Krycka, K.L.; Borchers, J.A.; Desautels, R.D.; van Lierop, J.; Huls, N.F.; Jackson, A.J.; Gruettner, C.; Ivkov, R. Internal Magnetic Structure of Nanoparticles Dominates Time-Dependent Relaxation Processes in a Magnetic Field. Adv. Funct. Mater. 2015, 25, 4300-4311. [CrossRef]

88. Guibert, C.; Dupuis, V.; Peyre, V.; Fresnais, J. Hyperthermia of Magnetic Nanoparticles: Experimental Study of the Role of Aggregation. J. Phys. Chem. C 2015, 119, 28148-28154. [CrossRef]

89. Ruta, S.; Chantrell, R.; Hovorka, O. Unified Model of Hyperthermia via Hysteresis Heating in Systems of Interacting Magnetic Nanoparticles. Sci. Rep. 2015, 5, 9090. [CrossRef] [PubMed]

90. Dennis, C.L.; Jackson, A.J.; Borchers, J.A.; Ivkov, R.; Foreman, A.R.; Lau, J.W.; Goernitz, E.; Gruettner, C. The Influence of Collective Behavior on the Magnetic and Heating Properties of Iron Oxide Nanoparticles. J. Appl. Phys. 2008, 103, 07A319. [CrossRef]

91. Niculaes, D.; Lak, A.; Anyfantis, G.C.; Marras, S.; Laslett, O.; Avugadda, S.K.; Cassani, M.; Serantes, D.; Hovorka, O.; Chantrell, R.; et al. Asymmetric Assembling of Iron Oxide Nanocubes for Improving Magnetic Hyperthermia Performance. ACS Nano 2017, 11, 12121-12133. [CrossRef]

92. Sadat, M.E.; Patel, R.; Sookoor, J.; Bud'ko, S.L.; Ewing, R.C.; Zhang, J.; Xu, H.; Wang, Y.; Pauletti, G.M.; Mast, D.B.; et al. Effect of Spatial Confinement on Magnetic Hyperthermia via Dipolar Interactions in Fe3O4 Nanoparticles for Biomedical Applications. Mater. Sci. Eng. C 2014, 42, 52-63. [CrossRef]

93. Mues, B. Bauer, B., Ortega, J., Buhl, EM., Teller, H., Gries, T., Schmitz-Rode, T., Slabu, I. Assessing Hyperthermia Performance of Hybrid Textile Filaments: The Impact of Different Heating Agents. J. Magn. Magn. Mater. 2021, 519, 167486. [CrossRef]

94. Kozissnik, B.; Bohorquez, A.C.; Dobson, J.; Rinaldi, C. Magnetic Fluid Hyperthermia: Advances, Challenges, and Opportunity. Int. J. Hyperthermia 2013, 29, 706-714. [CrossRef]

95. Hergt, R.; Dutz, S. Magnetic Particle Hyperthermia-Biophysical Limitations of a Visionary Tumour Therapy. J. Magn. Magn. Mater. 2007, 311, 187-1926. [CrossRef] 
96. Kossatz, S.; Ludwig, R.; Dähring, H.; Ettelt, V.; Rimkus, G.; Marciello, M.; Salas, G.; Patel, V.; Teran, F.J.; Hilger, I. High Therapeutic Efficiency of Magnetic Hyperthermia in Xenograft Models Achieved with Moderate Temperature Dosages in the Tumor Area. Pharm. Res. 2014, 31, 3274-3288. [CrossRef] [PubMed]

97. Rubia-Rodríguez, I.; Santana-Otero, A.; Spassov, S.; Tombácz, E.; Johansson, C.; Thanh, N.T.K.; Besenhard, M.O.; Wilhelm, C.; Gazeau, F.; Harmer, Q.; et al. Whither Magnetic Hyperthermia? A Tentative Roadmap. Materials 2021, 14, 706. [CrossRef] [PubMed]

98. Spirou, S.V.; Basini, M.; Lascialfari, A.; Sangregorio, C.; Innocenti, C. Magnetic Hyperthermia and Radiation Therapy: Radiobiological Principles and Current Practice. Nanomaterials 2018, 8, 401. [CrossRef] [PubMed]

99. Dobšíček Trefná, H.; Schmidt, M.; van Rhoon, G.C.; Kok, H.P.; Gordeyev, S.S.; Lamprecht, U.; Marder, D.; Nadobny, J.; Ghadjar, P.; Abdel-Rahman, S.; et al. Quality Assurance Guidelines for Interstitial Hyperthermia. Int. J. Hyperthermia 2019, 36, 276-293. [CrossRef] 